\title{
Comparative Transcriptomic Analysis of Pseudomonas aeruginosa Isolates from ICU Patients with Acute and Chronic Pneumonia
}

\author{
Jayasimha Rao, PhD ${ }^{1,2,3^{*}}$, Adenike Adenikinju, MD', James M. Gray, MS ${ }^{4}$, Lily Colpitts, \\ $M D^{1,5}$, Alyson Prorock, BS ${ }^{6}$, Yongde Bao, PhD ${ }^{6,7}$, Thomas M. Kerkering, MD ${ }^{1,2,3}$, Dorothy \\ C. Garner, $M D^{1,2}$ and Roderick V. Jensen, $P h D^{8 *}$
}

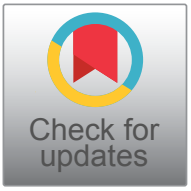

${ }^{1}$ Internal Medicine, Division of Infectious Disease, Virginia Tech Carilion School of Medicine, Roanoke, Virginia, USA

2Internal Medicine, Division of Infectious Disease, Carilion Medical Center, Roanoke, Virginia, USA

${ }^{3}$ Center for Emerging, Zoonotic, and Arthropod-borne Pathogens, Virginia Tech, Blacksburg, Virginia, USA

${ }^{4}$ Carilion Clinic Research and Development, Roanoke, Virginia, USA

${ }^{5}$ Birmingham ID and Infusion, Birmingham, AL, USA

${ }^{6}$ MD-DMED SOM Core Facilities, University of Virginia, Charlottesville, Virginia, USA

${ }^{7}$ MD-MICR Microbiology, University of Virginia, Charlottesville, Virginia, USA

${ }^{8}$ Department of Biological Sciences, Virginia Tech, Blacksburg, Virginia, USA

*Corresponding author: Jayasimha Rao, PhD, Internal Medicine, Division of Infectious Disease, Virginia Tech Carilion School of Medicine, 101 Elm Avenue, Roanoke, VA 24013, USA, Tel: 540-529-5154; Roderick V. Jensen, PhD, Department of Biological Sciences, Derring Hall Room 2125, 926 West Campus Drive, Blacksburg, VA 24061, USA

\begin{abstract}
Multidrug-resistant (MDR) and virulent pathogenic strains of Pseudomonas aeruginosa $(\mathrm{Pa})$ are among the most dangerous pathogens in healthcare-associated infections. In this study, a comparative analysis was performed on two clinical $P$ a strains from pneumonia patients, 1) An acute strain (CMC-115) and 2) A chronic multidrug- and carbapenemresistant strain (CMC-097) with distinct phenotypic and genetic characteristics. A transcriptome analysis using both the Pseudomonas DNA GeneChip microarray and Illumina RNA-Seq technologies was carried out for both strains at early-stationary growth phase in laboratory culture. The comparative transcriptomic analysis identified 134 genes differentially expressed $\geq 4.0$-fold by both technologies. Between the two strains, which included virulence genes such as flagellar, pili, pyoverdine, and phenazine genes, that were higher in the acute strain, CMC-115, and type 3 secretory system (T3SS) and pyochelin biosynthesis genes, which were higher in the chronic strain, CMC-097. In particular, the DNA microarrays suggested and the RNASeq analysis confirms the type 3 secretory system genes were completely missing from the acute strain, CMC-115.
\end{abstract}

The combined analysis using the RNA-Seq and DNA microarray methods also identified important genes that were either missing or highly divergent from the Reference PAO1 genome used for the DNA microarray design. For example, the RNA-Seq data identified an operon containing several multidrug resistance genes: aacA27, $\beta$-lactamase ${ }_{\text {OXA-2 }}\left(b_{\text {OXA-2 }}\right)$, qacE $\Delta 1$, sul1, and GNAT-N, in the chronic strain, CMC-097. This comparative analysis revealed several important differences in gene expression between the two strains that may lead to identification of targets for better therapy and hospital management.

Keywords

Pseudomonas aeruginosa, Ventilator associated pneumonia, Transcriptome analysis, Acute and chronic infections

\section{Introduction}

Pseudomonas aeruginosa $(P a)$ is an increasingly common opportunistic pathogen causing infection in immunocompromised and hospitalized patients, leading to hospital-acquired pneumonia (HAP). Patients

Citation: Rao J, Adenikinju A, Gray JM, Colpitts L, Prorock A, et al. (2021) Comparative Transcriptomic Analysis of Pseudomonas aeruginosa Isolates from ICU Patients with Acute and Chronic Pneumonia. Int Arch Med Microbiol 3:012. doi.org/10.23937/2643-4008/1710012

Accepted: June 15, 2021: Published: June 17, 2021

Copyright: (C) 2021 Rao J, et al. This is an open-access article distributed under the terms of the Creative Commons Attribution License, which permits unrestricted use, distribution, and reproduction in any medium, provided the original author and source are credited. 
on ventilators are particularly vulnerable, where $P a$ invades the lower respiratory tract leading to ventilatorassociated pneumonia (VAP), increasing the risk of mortality as much as $30 \%$ in intensive-care units (ICUs) [1-4]. In addition, $P a$ has become increasingly resistant to carbapenems. A 2016 World Health Organization survey ranked carbapenem-resistant (CR) $P a$ as the second most critical-priority bacterium among 20 antimicrobial-resistant bacterial species [5].

$P$. aeruginosa has a broad arsenal of virulence factors involved during chronic and acute infections in HAP. Their production is finely coordinated by many cellular regulators in processes interconnected with various metabolic pathways. One example is quorum sensing (QS), which regulates at least $10 \%$ of $P a$ genes based on local bacterial density as well as other factors $[6,7]$. Apart from the transcriptomic expression, a subproteomic approach has led to identification and characterization of several periplasmic, membrane, or secreted $\mathrm{Pa}$ proteins as potential virulence factors [8-10]. One of the primary clinical challenges of managing $P a$ infections is that they exist in either acute and chronic forms, but in a chronically ill patient be very challenging to distinguish one from another $[11,12]$. Many proteins are involved in acute and chronic pathogenesis such as adhesion, secreted proteins, toxins, autoinducers, enzymes, and acquired antibiotic resistance genes. Additionally, in recent years, multidrug-resistant (MDR) $P a$ clones have caused outbreaks of HAP worldwide [13,14]. This leads to an interesting arrangement between intrinsic virulence factors and acquired MDR genes of strains causing acute and chronic infections $[15,16]$. The relationship between virulence and resistance in $\mathrm{Pa}$ remains poorly understood.

Acute infections caused by $P a$ often spread rapidly in host tissues, causing organ damage and sepsis with increased mortality rates. The major virulence determinants for acute infections are related to secreted toxins [17]. For example, the pyoverdine biosynthesis genes and receptors ( $p v d Q$ to $p v d R$ locus and $p v d A$ and $f p v A$ ) generate secreted sidephores that are able to strip iron from host cells and transport it back to the bacterial cell for utilization in multiple metabolic pathways [18-20]. Similarly, the phenazine operons (phzl and $p h z I I)$ and genes $(p h z H, p h z M$, and $p h z S)$ encode precursor proteins involved in the formation of three phenazine compounds passively secreted by $\mathrm{Pa}$ and 1-hydroxyphenazine, and phenazine-1-carboxamide $[21,22]$ that are responsible for increasing intracellular oxidative stress in the host tissue.

In contrast, chronic HAP is caused by $P a$ infections that fail to clear through the normal host innate and adaptive immune system or antibiotic treatment and often persist formonths or even years without resolution. Chronic isolates typically overproduce alginate, which enhances adhesion to tracheal epithelial cells [23]. The alginate, an exopolysaccharide, inhibits opsonic phagocytosis [24] and promotes resistance to reactive oxygen molecules [25-27]. In addition, the long duration of the chronic infection increases the development of multidrug-resistance (MDR), including CR strains [2832]. Earlier studies have identified important virulence factors for chronic $\mathrm{Pa}$ infections that are involved in bacterial attachment during colonization, nutrient acquisition, biofilm formation and resistance to the immune system and antimicrobials [33-35].

$P$. aeruginosa has incredible metabolic versatility, generally attributed to its genomic diversity [36,37]. In order to understand the pathogenesis of distinct strains of $P a$ that cause acute and chronic infections, it is essential to identify and characterize the genetic determinants associated with the differences in virulence factors, as well as to provide information on novel mechanisms of antibiotic resistance.

To investigate the genetic determinants for acute and chronic $P a$ infections, we have performed a comparative transcriptomic analysis of $P a$ isolates from patients with hospital-acquired acute and chronic pneumonia. In this study, we used both DNA microarrays and RNA-Seq for differential gene expression analysis of two clinical isolates; 1) CMC-115, a non-MDR strain collected from an acute pneumonia patient and 2) CMC-097, an MDR strain, including carbapenem-resistance (MDR-CR), from a chronic pneumonia patient. We found that many of the gene expression differences identified between the acute and chronic isolates by both DNA microarrays and RNA-Seq using the PAO1 (NC_002516.2) gene sequences as reference [38], were in good concordance and consistently revealed differential expression in at least 11 operons. These differentially expressed operons contained many interesting genes responsible for clinical differences in the acute or chronic isolates such as multidrug efflux, flagella, pyoverdine, phenazine, type 6 secretion system (T6SS), type 3 secretion system (T3SS), and metabolic genes such as glucose transporters and pyochelin biosynthesis genes.

The RNA-Seq data also provided additional insight into genetic and transcriptomic differences between the two strains. For example, the alignment of the RNA-Seq transcripts to the PAO1 genome revealed that some genes are completely missing from the genome of one strain or the other and a number of genes were found to have so many mutations relative to the PAO1 that their expression could not be reliably measured using either conventional DNA Microarray or RNA-Seq analysis. Moreover, the de novo assembly of the RNA-Seq reads that failed to align to the PAO1 reference genome readily identified additional genetic components in the clinical samples such as the presence of the carbapenemase producing $\beta$-lactamase oxacillinase- 2 $\left(b / a_{\text {OXA-2 }}\right)$ gene responsible for carbapenem resistance in the CMC-097 chronic isolate and its absence in the CMC-115 acute isolate. 


\section{Materials and Methods}

\section{Clinical isolates of Pseudomonas aeruginosa $(\mathrm{Pa})$}

The Carilion Clinic Institutional Review Board approved this prospective study, which was conducted during 2010-2012. In this study, two clinical strains of $P a$ from the Carilion Medical Center (CMC) were used. The two clinical non-mucoid strains were selected from 38 clinical strains, based on their phenotypic expression and clinical outcomes: 1) Pa CMC-115, nonmultidrug-resistant, pyoverdine producing strain was collected from a patient with acute pneumonia who was on a ventilator; and 2) Carbapenem-resistant (CR) PaCMC-097, a broadly multidrug-resistant strain was collected from a patient on chronic ventilator support without symptoms of acute infection as described in Table 1. Clinical strains were collected from the Microbiology Laboratory at CMC, and each strain was grown on a blood agar (tryptic soy agar; TSA with $5 \%$ sheep blood) plate and transported to Carilion Basic Science Research Laboratory (CBSRL); glycerol stocks were stored at $-70^{\circ} \mathrm{C}$ freezer. Tests for biochemical properties of the isolates, including antimicrobial susceptibility, were performed using a VITEK 2 automated system (bioMérieux). Antimicrobial susceptibility readings were recorded according to Clinical and Laboratory Standards Institute (CLSI) guidelines (http://clsi.org/m100/).

\section{Growth curve and sample collections}

A single colony from CMC-115 and CMC-097 strain was inoculated in Lysogeny broth (LB) and incubated at $37^{\circ} \mathrm{C}$ at 200 revolutions per minute (rpm) for $18 \mathrm{~h}$, after which they were diluted 1:100 in $50 \mathrm{ml}$ fresh LB medium in three replicates. Growth was then periodically measured at $\mathrm{OD}_{600}$. For RNA isolation, $10 \mathrm{ml}$ of each bacterial sample from each replicate was collected at early stationary growth phase of 5 -hour $\left(1.618 \mathrm{OD}_{600}\right)$, indicated by asterisk in Figure 1. Bacterial cells were pelleted by centrifugation at $3220 \times \mathrm{g}$ for $15 \mathrm{~min}$ at 4 ${ }^{\circ} \mathrm{C}$. For Western blot analysis, $P$. aeruginosa strains were grown for $11 \mathrm{~h}$ and samples were collected every hour from $5 \mathrm{~h}$ onward, normalizing the bacterial suspensions to an $\mathrm{OD}_{600}$ of 0.1 and processing always the same number of bacteria.

\section{Motility assay}

Minimal medium that contained peptone broth ( $10 \mathrm{~g} /$ liter peptone and $5 \mathrm{~g} /$ liter $\mathrm{NaCl}$ ) with $0.6 \%$ agar were used in subsurface twitching motility assay [39]. Briefly, the clinical cultures of CMC-115 and CMC-097 strains were grown overnight in LB medium and transferred to twitching plates $(0.6 \%$ agarose in LB medium). Plates were stabbed with a sterile blunt inoculum loop and incubated at $28^{\circ} \mathrm{C}$ for 72 hours. Agar was removed with a sterile spatula and stained with $0.1 \%$ crystal violet (CV) on the plate and left to set for 5 minutes. Then, $\mathrm{CV}$ was washed with water several times and twitching zones were measured as radius of movement and expressed in millimeter $(\mathrm{mm})$. Experiments were performed in triplicate.

\section{Pyoverdine production}

For the pyoverdine assay, LB medium was inoculated

Table 1: Clinical features and antimicrobial susceptibility of $P$. aeruginosa $(P a)$ strains.

\begin{tabular}{|c|c|c|c|c|}
\hline Clinical evaluations & \multicolumn{2}{|c|}{ Pa CMC-097 } & \multicolumn{2}{|c|}{ Pa CMC-115 } \\
\hline Fever & \multicolumn{2}{|c|}{ Yes (104.7 F) } & \multicolumn{2}{|c|}{ Yes $(101.1 \mathrm{~F})$} \\
\hline Cough & \multicolumn{2}{|l|}{ Yes } & \multicolumn{2}{|l|}{ Yes } \\
\hline Sputum Production & \multicolumn{2}{|l|}{ Yes } & \multicolumn{2}{|l|}{ Yes } \\
\hline$\Delta$ quantity/color & \multicolumn{2}{|l|}{ No } & \multicolumn{2}{|l|}{ Yes } \\
\hline Increase $\mathrm{O}_{2}$ required & \multicolumn{2}{|l|}{ No } & \multicolumn{2}{|l|}{ Yes } \\
\hline Infiltrate on CXR & \multicolumn{2}{|l|}{ No } & \multicolumn{2}{|l|}{ No } \\
\hline Elevated WBC & \multicolumn{2}{|c|}{ Yes (11.2) } & \multicolumn{2}{|c|}{ Yes (13.8) } \\
\hline Chronic Vent & \multicolumn{2}{|l|}{ Yes } & \multicolumn{2}{|l|}{ No } \\
\hline Recent Pseudomonas Pneumonia & \multicolumn{2}{|c|}{ Yes (2 weeks PTA) } & \multicolumn{2}{|l|}{ No } \\
\hline MDR Isolate & \multicolumn{2}{|l|}{ Yes } & \multicolumn{2}{|l|}{ No } \\
\hline Alternative DX & \multicolumn{2}{|c|}{ Yes (PICC-line infection) } & \multicolumn{2}{|c|}{ Yes (E. coli, UTI) } \\
\hline Assessment & \multicolumn{2}{|c|}{ Late Colonization or Chronic } & \multicolumn{2}{|c|}{ Early Colonization Vs. Early Infection } \\
\hline Antimicrobial testing ${ }^{*}$ & \multicolumn{4}{|c|}{ Susceptibility results and interpretation } \\
\hline Amikacin & 16 & Sensitive & $<=2$ & Sensitive \\
\hline Ciprofloxacin & $>=4$ & Resistant & 2 & Sensitive \\
\hline Gentamicin & $>=16$ & Resistant & $<=1$ & Sensitive \\
\hline Meropenem & $>=16$ & Resistant & $<=0.25$ & Sensitive \\
\hline Tobramycin & $>=16$ & Resistant & $<=0.25$ & Sensitive \\
\hline Piperacilin/Tazobactam & $>=128$ & Resistant & $<=1$ & Sensitive \\
\hline
\end{tabular}

${ }^{*}$ MICs determined by using ASTGN45 card. 

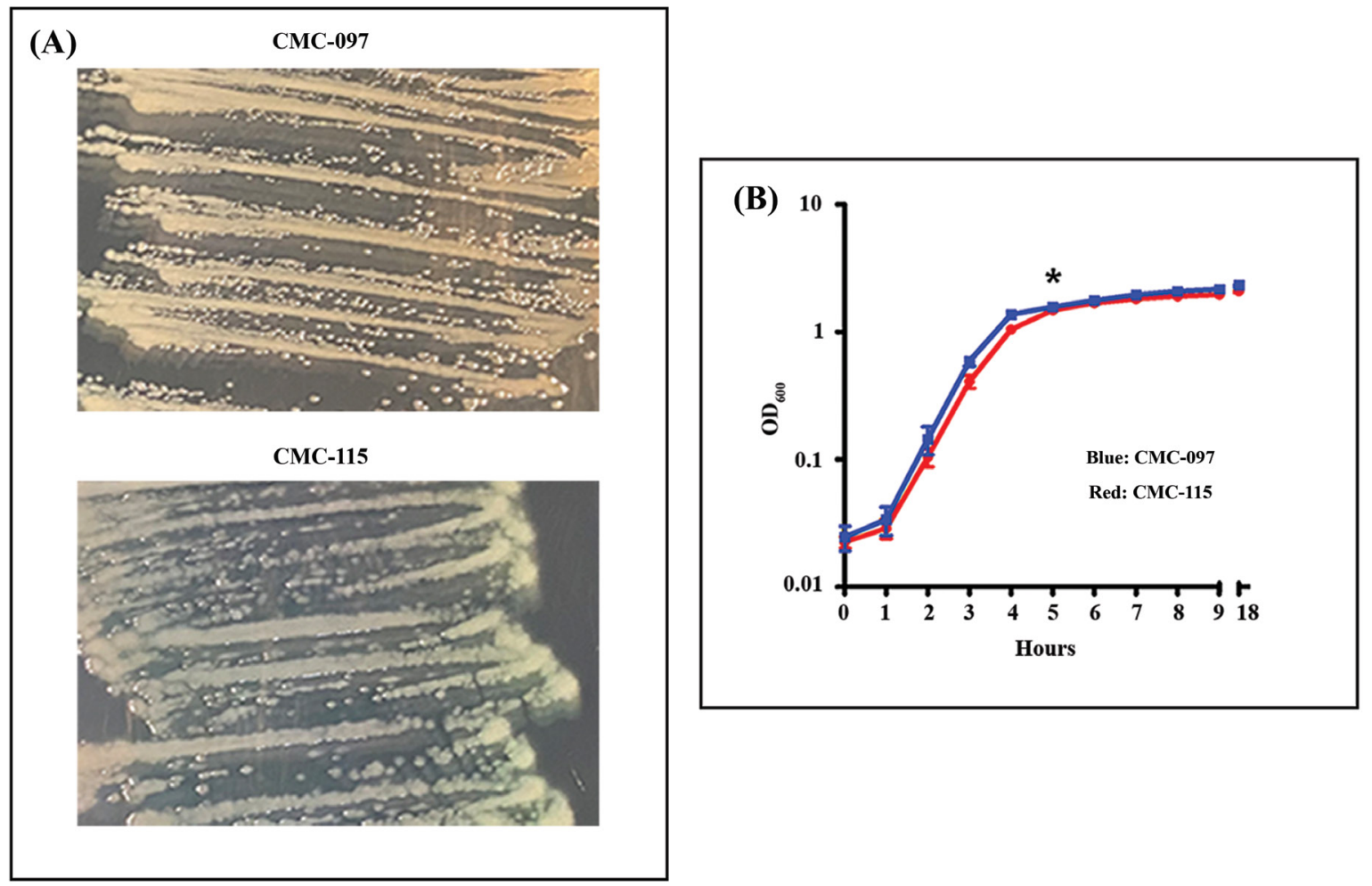

Figure 1: Phenotypic Characterization of CMC-097 and CMC-115. A) Representative figure shows each strain grown on trypticase soy agar. CMC-097 growing pale yellow non-mucoid colonies compared to the green non-mucoid colonies of CMC-115; B) CMC-115 (blue line) and CMC-115 (red line) grown in the same conditions in LB cultures. Both strains show similar growth curves as measured at $\mathrm{OD}_{600}$ during 1-9 and after 18 hours cultured at $37^{\circ} \mathrm{C}$ at $200 \mathrm{rpm}$. The data shown are from two independent experiments with mean values and \pm standard deviation.

with $P a$ strains CMC-115, CMC-097, and PAO1, a laboratory strain (each strain normalized to $\mathrm{OD}_{600}=0.01$ ) and incubated at $37^{\circ} \mathrm{C}$ and $200 \mathrm{rpm} 18$ hours. Bacterial growth was measured at $\mathrm{OD}_{600} \mathrm{~nm}$ and cultures were centrifuged at $200 \times \mathrm{g}$ for $30 \mathrm{~min}$ at $4{ }^{\circ} \mathrm{C}$. Supernatants were filtered $(0.4 \mu \mathrm{m})$ to obtain sterile Pseudomonas culture free supernatants (PCFs), as described earlier [40]. Each group in this experiment contained at least three replicates. For all PCFs, pyoverdine production was measured at $\mathrm{OD}_{405} \mathrm{~nm}$. Measurements were normalized to bacterial growth using the formula: Relative PYOV production $=O D_{405} / O D_{600}$.

Total RNA isolation: Total RNA was isolated using the Ribo Pure Bacterial (RNAwiz) kit (Ambion) and the contaminating DNA was removed with the DNA-free kit (Ambion) following the manufacturer's specification. RNA quality was assessed using Experion Automated Electrophoresis System (BioRad), and selected samples were also examined in a Nano RNA 600 Agilent chip in a BioAnalyzer 2100.

Microarray analysis: The $P$. aeruginosa Affymetrix GeneChip Pae_G1a microarray was used for differential gene expression analysis. Total RNA from 5-hour growth of CMC-115 and CMC-097 were run in duplicates following the manufacturer's protocol (https://www. affymetrix.com/analysis/netaffx/) at DNA Sciences Core Facility at the University of Virginia. Gene expression levels were determined using the RMA method in the "Oligo" package in R/Bio Conductor (https:// www.bioconductor.org/). The averages of the logged expression values for the duplicate samples were computed using Microsoft Excel and the average fold change between CMC-115 and CMC-097 was determined for these two isolates along with student's t-test $p$-value for the differences.

RNA-sequencing and library preparation: A RIN (RNA Integrity Number) of 7.5 or above is required to qualify for RNA-Seq. An amount of 1-2 $\mu \mathrm{g}$ of total RNA is used for RNA-Seq library preparation. Sequencing libraries for the RNA-Seq were constructed following the instruction of the Illumina TrueSeq RNA sample preparation by the manufacturer. Briefly, the RNA was further purified, and then fragmented in a beadbound reaction. This was followed by the first strand cDNA synthesis and second strand cDNA synthesis. The resulting cDNA was end-repaired and then adenylated. Ligation was then performed according to the choice of the protocols to the specified adapters. The ligation products, after purification, were then PCR amplified where the adaptor and indices were incorporated. The libraries were then validated for concentration and quality by Qubit fluorospectrometer and Agilent Bioanalyzer, respectively.

Next-Gen sequencing: Individually bar-coded sequencing libraries were first pooled in an equal-molar manner, which were then diluted to $10 \mathrm{nM}$ and dena- 
tured in 0.1 sodium hydroxide and adjusted to $12 \mathrm{pM}$ as final concentration for loading into a single lane of an Illumina NextSeq 150 V2 High Output flow cell. After that, the flow cell was transferred to the Illumina NextSeq 500 for a paired-end sequencing of 75 sequencing cycles, according to manufacturer's recommended protocol (https://icom.illumina.com/). The RNA-Seq analysis and data discussed in this publication have been deposited in the NCBI Gene Expression Omnibus (GEO; http://www.ncbi.nlm.nih.gov/geo/) and are accessible through GEO series accession number GSE180499.

Processing of Illumina data: The Illumina pairedend fastq files for the three replicate samples for each of the two strains were aligned to the annotated PAO1 reference genome (NC_002561) using the Geneious 11 software (Biomatters, Ltd) with the default "low sensitivity" setting, allowing $10 \%$ mismatch. The read counts aligning to each of the annotated genes were normalized by dividing by the number of mapped reads for each sample and multiplying by one million to compute the transcripts per million (TPM) expression levels.

SDS-PAGE and Western blot analysis: For SDS-PAGE and Western blotting analysis, normalized cells pellets were directly lysed in Laemmli buffer [41] and boiled for 10 minutes at $100^{\circ} \mathrm{C}$, and total proteins were separated on the $8-16 \%$ SDS-PAGE gels using the Criterion gel system (BioRad), as described elsewhere [7]. Blots were probed with anti-PcrV antibodies raised in rabbits (a kind gift from Arne Rietsch) was diluted at 1:3000 in killer filler (KF) reagent, as described elsewhere [7], and incubated overnight at $4{ }^{\circ} \mathrm{C}$. Immunodetection was performed with secondary antibody HRP-conjugated goat anti-rabbit IgG at a dilution of 1:5000 in PBS-T. The blots were washed three times with PBS-T followed by PBS for five min each. Finally, reactivity was visualized using enhanced chemiluminescence (ECL Kit) according to the manufacturer's protocol (Amersham). Then, the same blot was stripped with stripping solution and reprobed with anti-RpoA mouse monoclonal antibody (BioLegend) in 1:5000 and detection performed with HRP-conjugated goat anti-mouse IgG at a dilution of 1:5000 and visualized as described earlier.

\section{Polymerase chain reaction (PCR) for pcrV gene}

PCR was carried out using primers for pcrV gene and rahU gene used as comparative product by using genomic DNA (gDNA) as a template, as described earlier [42]. The PCR was set up as follows: $23 \mu \mathrm{l}$ of platinum Taq PCR Supermix (Invitrogen) including 0.5 $\mu \mathrm{l}$ of forward and reverse primers for pcrV and rahU together, then $2 \mu \mathrm{l}$ of DNA template from each strain was added to give a final volume of $25 \mu \mathrm{l}$. The negative control contained Supermix, no gDNA template, and $2 \mu \mathrm{l}$ of sterile water. Reactions were performed in a thermocycler (Biorad) as follows: $94^{\circ} \mathrm{C}, 2 \mathrm{~min}$, followed by 36 cycles of $94^{\circ} \mathrm{C}, 30 \mathrm{sec}, 58^{\circ} \mathrm{C}, 30 \mathrm{sec}, 68^{\circ} \mathrm{C}$ one min and a final extension step of $68^{\circ} \mathrm{C}$ for seven min. PCR products were visualized on a $1 \%$ agarose gel, stained with $0.5 \mathrm{mg} / \mathrm{ml}$ of ethidium bromide and viewed under UV light in Bio-Imager (Biorad).

\section{Results}

\section{Clinical Strains of Pseudomonas aeruginosa}

In this study, two $P$. aeruginosa $(P a)$ clinical isolates were collected from ICU patients with acute and chronic pneumonia. The acute strain, CMC-115, was collected from a patient on ventilator support with acute infection, while the chronic strain, CMC-097, was collected from a patient on ventilator support without symptoms of acute infection and who had been repeatedly culture positive for $P a$. The clinical features of both strains are summarized in Table 1.

\section{Phenotypic characterization of the acute and chronic Pa strains}

Figure $1 \mathrm{~A}$ shows that both strains on TSA plates appeared to be non-mucoid but CMC-097 exhibited white colonies while the CMC-115 colonies showed a distinct greenish pigment. In LB culture, both strains had similar growth curves, shown in Figure 1B. In addition, Figure 2A showed that acute CMC-115 isolate exhibited a significant increase in twitching motility compared with the chronic CMC-097 strain $(P=0.0128)$. Moreover, Figure 2B shows that the relative production of pyoverdine (PYOV) in the culture supernatant was significantly higher in the acute CMC-115 strain than the chronic CMC-097 strain $(P<0.0001)$, which is consistent with color differences in the colonies in Figure $1 \mathrm{~A}$.

Another important difference between the two strains is that the chronic strain CMC-097 was found to be multidrug-resistant, including carbapenemresistance (MDR-CR), while the acute strain $\mathrm{Pa}$ CMC-115 was non-MDR, as listed in Table 1. The antibiotic susceptibility was tested in vitro by VITEK2 $2^{\circ}$ automated system to determine the minimal inhibitory concentrations (MIC) for the CMC-097 and CMC-115 strains. The clinical isolate CMC-097 was resistant to carbapenems, according to the CLSI definition [43] with the respective CLSI breakpoint for imipenem and/or meropenem considered as $\geq 8 \mu \mathrm{g} / \mathrm{mL}$ [44].

Gene expression differences between the CMC115 and CMC-097 clinical isolates of $P$. aeruginosa using DNA microarrays

To determine genome-wide transcriptional differences between the acute CMC-115 and chronic CMC-097 strains, we first performed microarray experiments on two replicate samples for each strain at early-stationary growth phase in culture (five-hour time point). The transcriptome analysis performed using the Affymetrix GeneChip microarray for $P$. aeruginosa, identified 151 gene probesets that were increased or decreased in the 


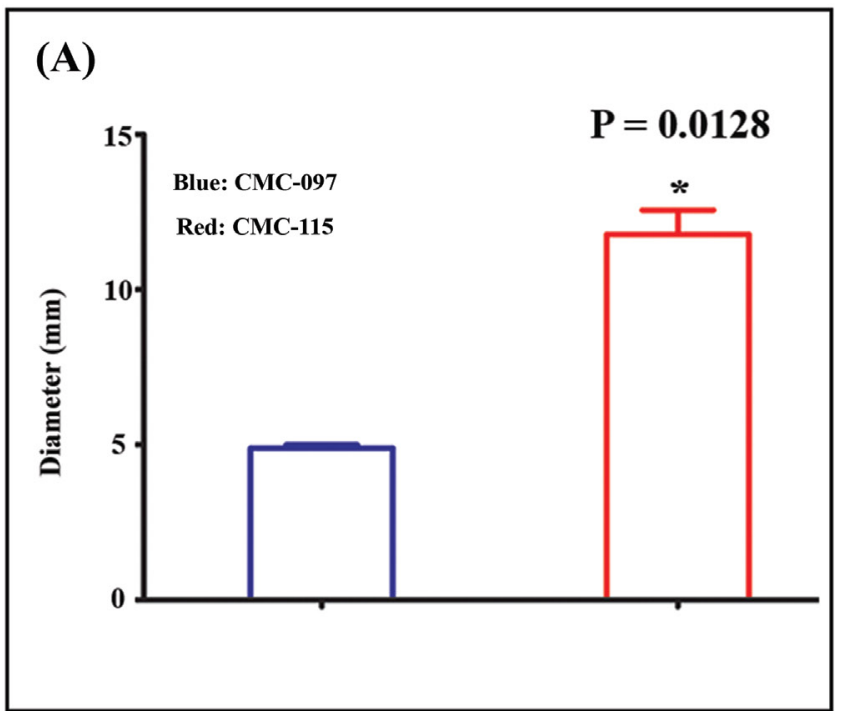

(B)

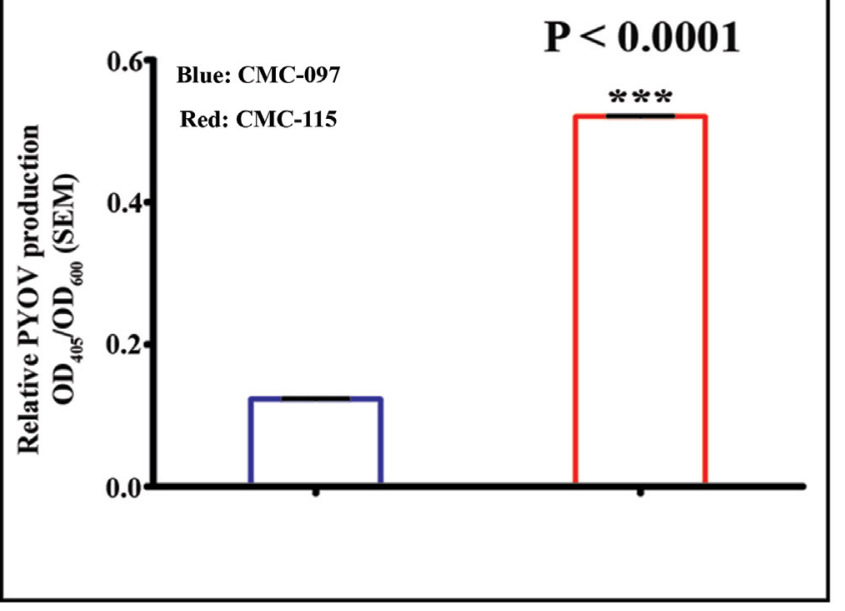

Figure 2: Twitching motility and pyoverdine production by CMC-115 and CMC-097. A) Representative bar presentation of CMC-097 and CMC-115 colony diameters are shown. CMC-115 showed increase twitching phenotype resulting in increased diameter on the plastic surface stained with $0.1 \% \mathrm{CV}$ and measured by ruler. Three replicates of each were performed. Asterisk indicates $\mathrm{P}=0.0128$, decreased motility in $\mathrm{CMC}-097$; $\mathrm{B}$ ) Planktonic $\mathrm{Pa}$ culture filtrate (PCFs) and pyoverdine measurement. Bacterial growth was measured at $\mathrm{OD}_{600} \mathrm{~nm}$ in a spectrophotometer. Each group in this experiment contained at least 3 replicates. For all PCFs, pyoverdine production was measured at $\mathrm{OD}_{405} \mathrm{~nm}$. Measurements were normalized to bacterial growth using the formula: Relative PYOV production $=\mathrm{OD}_{405} / O D_{600}$. Each group in this experiment contained at least 3 replicates. Three asterisks indicate $\mathrm{P}<0.0001$, decrease in pyoverdine production in CMC-097.

Table 2: Up-regulated annotated genes in Pa CMC-115.

\begin{tabular}{|c|c|c|c|c|c|}
\hline Locus_tag & $\begin{array}{l}\text { Microarray } \\
\text { Fold Ratio }\end{array}$ & $\begin{array}{l}\text { RNA-Seq } \\
\text { Fold Ratio }\end{array}$ & $\begin{array}{l}\text { Gene } \\
\text { Name }\end{array}$ & Product & $\begin{array}{c}\text { Common Pathways/Functional } \\
\text { Classifications }\end{array}$ \\
\hline PA0705 & 8.48 & $\infty$ & $\operatorname{mig} A$ & Alpha-1,6-rhamnosyltransferase & $\begin{array}{l}\text { Quorum sensing/Cell wall/LPS/ } \\
\text { capsule/Putative enzymes }\end{array}$ \\
\hline PA0723 & 4.79 & 4.94 & $c o a B$ & Phage coat protein B & $\begin{array}{l}\text { Related to phage/Transposon/or } \\
\text { Plasmid }\end{array}$ \\
\hline PA0745 & 4.3 & 2.6 & $d s p L$ & & Enoyl-CoA hydrastase \\
\hline PA0958 & 8.36 & 95.89 & oprD & Porin D & $\begin{array}{l}\text { Two-component system/beta- } \\
\text { Lactam resistance/Transport of small } \\
\text { molecules }\end{array}$ \\
\hline PA1092 & 84.71 & 41.35 & flic & B-type flagellin & $\begin{array}{l}\text { Flagella assembly/Two-component } \\
\text { system /Motility \& Attachment }\end{array}$ \\
\hline PA1093 & 9.35 & $\infty$ & flaG & Hypothetical protein & $\begin{array}{l}\text { Flagella assembly/Hypothetical, } \\
\text { unclassified, unknown }\end{array}$ \\
\hline PA1094 & 16.02 & $\infty$ & fliD & $\begin{array}{l}\text { B-type flagellar hook-associated } \\
\text { protein }\end{array}$ & $\begin{array}{l}\text { Flagella assembly/Cell wall/LPS/ } \\
\text { capsule/Motility \& Attachment }\end{array}$ \\
\hline PA1095 & 79.61 & $\infty$ & flis & B-type flagellar protein & Flagella assembly \\
\hline PA1135 & 4.4 & 3.0 & yedU & & $\begin{array}{l}\text { Molecular chaperone HSP31/ } \\
\text { glyoxalase }\end{array}$ \\
\hline PA1317 & 4.78 & 14.80 & суоА & $\begin{array}{l}\text { Cytochrome o ubiquinol oxidase } \\
\text { subunit II }\end{array}$ & Metabolic pathway/Energy metabolism \\
\hline PA1902 & 5.07 & 4.95 & phzD2 & Phenazine biosynthesis protein & $\begin{array}{l}\text { Quorum sensing/Phenazine } \\
\text { biosynthesis/Secreted Factor }\end{array}$ \\
\hline PA1903 & 4.80 & 5.17 & phzE2 & Phenazine biosynthesis protein & $\begin{array}{l}\text { Quorum sensing/Phenazine } \\
\text { biosynthesis/Secreted Factor }\end{array}$ \\
\hline PA1904 & 4.90 & 5.09 & phzF2 & $\begin{array}{l}\text { Trans-2,3-dihydro-3- } \\
\text { hydroxyanthranilate isomerase }\end{array}$ & $\begin{array}{l}\text { Quorum sensing/Phenazine } \\
\text { biosynthesis/Secreted Factor }\end{array}$ \\
\hline PA2246 & 4.3 & 2.4 & $b k d R$ & & $\begin{array}{l}\text { Bkd operon transcriptional regulator } \\
\text { BkrD }\end{array}$ \\
\hline PA2329 & 7.51 & 10.35 & & ABC transporter ATP-binding protein & Transport of small molecules \\
\hline
\end{tabular}




\begin{tabular}{|c|c|c|c|c|c|}
\hline PA2365 & 5.82 & 5.84 & hsiB3 & Hypothetical protein & $\begin{array}{l}\text { Biofilm formation/T6SS/Bacterial } \\
\text { secretion system }\end{array}$ \\
\hline PA2366 & 8.20 & 6.36 & hsiC3 & Uricase & $\begin{array}{l}\text { Biofilm formation/T6SS/Bacterial } \\
\text { secretion system }\end{array}$ \\
\hline PA2367 & 6.75 & 8.36 & hcp3 & Hypothetical protein & $\begin{array}{l}\text { Biofilm formation/T6SS/Bacterial } \\
\text { secretion system }\end{array}$ \\
\hline PA2368 & 7.51 & 8.18 & hsiF3 & Hypothetical protein & $\begin{array}{l}\text { T6SS/Hypothetical, unclassified, } \\
\text { unknown }\end{array}$ \\
\hline PA2385 & 5.62 & 20.24 & $p v d Q$ & Acyl-homoserine lactone acylase & $\begin{array}{l}\text { Pyoverdine synthesis/Adaptation, } \\
\text { Protection }\end{array}$ \\
\hline PA2393 & 13.99 & 17.21 & $p v d M$ & Dipeptidase & $\begin{array}{l}\text { Pyoverdine synthesis/Central } \\
\text { intermediary metabolism }\end{array}$ \\
\hline PA2394 & 13.71 & 17.97 & $p v d N$ & Pyoverdine biosynthesis protein & $\begin{array}{l}\text { Pyoverdine synthesis/Adaptation, } \\
\text { Protection }\end{array}$ \\
\hline PA2395 & 4.12 & 34.60 & $p v d O$ & Pyoverdine biosynthesis protein & $\begin{array}{l}\text { Pyoverdine synthesis/Adaptation, } \\
\text { Protection }\end{array}$ \\
\hline PA2404 & 9.09 & 5.09 & $f p v H$ & Hypothetical protein & Membrane protein \\
\hline PA2405 & 6.08 & 7.27 & fpvJ & Hypothetical protein & Hypothetical, unclassified, unknown \\
\hline PA2406 & 4.56 & 4.46 & fpvK & Hypothetical protein & Hypothetical, unclassified, unknown \\
\hline PA2407 & 4.04 & 5.56 & $f p v C$ & Adhesion protein & $\begin{array}{l}\text { ABC transporters/Motility \& } \\
\text { Attachment/Transport of small } \\
\text { molecules }\end{array}$ \\
\hline PA2444 & 5.59 & 5.50 & glyA2 & Serine hydroxymethyl transferase & $\begin{array}{l}\text { Biosynthesis of secondary metabolites/ } \\
\text { Amino acid biosynthesis and } \\
\text { metabolism }\end{array}$ \\
\hline PA2445 & 8.46 & 8.25 & gcvP2 & Glycine dehydrogenase & $\begin{array}{l}\text { Biosynthesis of secondary metabolites/ } \\
\text { Amino acid biosynthesis and } \\
\text { metabolism/Central intermediary } \\
\text { metabolism }\end{array}$ \\
\hline PA2564 & 17.07 & 30282.00 & tam & Trans-aconitate 2-methyltransferase & Hypothetical, unclassified, unknown \\
\hline PA2688 & 4.6 & 3.5 & $p f e A$ & & Ferric enterobactin receptor \\
\hline PA4078 & 5.29 & 7.94 & & $\begin{array}{l}\text { Probable nonribosomal peptide } \\
\text { synthetase }\end{array}$ & Adaption, protection \\
\hline PA4142 & 10.44 & 9.17 & & Secretion protein & Protein secretion/export apparatus \\
\hline PA4144 & 5.83 & 7.28 & opmK & Hypothetical protein & $\begin{array}{l}\text { Two-component system/ beta-Lactam } \\
\text { resistance/Protein secretion/export } \\
\text { apparatus }\end{array}$ \\
\hline PA4205 & 23.13 & 98.52 & $\operatorname{mexG}$ & Hypothetical protein & Quorum sensing/Membrane protein \\
\hline PA4206 & 6.64 & 99.14 & mexH & $\begin{array}{l}\text { Resistance-nodulation-cell division } \\
\text { (RND) efflux membrane fusion } \\
\text { protein }\end{array}$ & $\begin{array}{l}\text { Quorum sensing/Transport of small } \\
\text { molecules }\end{array}$ \\
\hline PA4207 & 37.76 & 77.27 & $\operatorname{mexl}$ & $\begin{array}{l}\text { Resistance-nodulation-cell division } \\
\text { (RND) efflux transporter }\end{array}$ & $\begin{array}{l}\text { Quorum sensing/Membrane protein/ } \\
\text { Transport of small molecules }\end{array}$ \\
\hline PA4208 & 15.76 & 38.10 & opmD & Hypothetical protein & $\begin{array}{l}\text { Quorum sensing/Membrane protein/ } \\
\text { Transport of small molecules }\end{array}$ \\
\hline PA4468 & 5.89 & 6.55 & sodM & Superoxide dismutase & $\begin{array}{l}\text { Superoxide radicals degradation/ } \\
\text { Adaptation, protection }\end{array}$ \\
\hline PA4470 & 6.54 & 6.82 & fumC1 & Fumarate hydratase & TCA cycle/Energy metabolism \\
\hline PA4471 & 5.09 & 5.72 & fagA & Hypothetical protein & Hypothetical, unclassified, unknown \\
\hline PA4525 & 125.07 & $\infty$ & pilA & Type 4 fimbrial protein & $\begin{array}{l}\text { Two-component system/Pilin } \\
\text { biosynthesis/Motility \& Attachment }\end{array}$ \\
\hline PA4590 & 8.23 & 11.04 & Pra & Protein activator & $\begin{array}{l}\text { Transport of small molecule/Carbon } \\
\text { compound catabolism }\end{array}$ \\
\hline PA5180 & 4.06 & 6.26 & $f d h D$ & Hypothetical protein & Hypothetical, unclassified, unknown \\
\hline PA5181 & 11.63 & 19.35 & & Oxidoreductase & Putative enzymes \\
\hline PA5415 & 4.5 & 3.3 & glyA1 & & Serine hydroxymethyltransferase \\
\hline
\end{tabular}


Table 3: Up-regulated annotated genes in carbapenem resistant $\mathrm{Pa}$ CMC-097.

\begin{tabular}{|c|c|c|c|c|c|}
\hline Locus_tag & $\begin{array}{l}\text { Microarray } \\
\text { Fold Ratio }\end{array}$ & $\begin{array}{l}\text { RNA-Seq } \\
\text { Fold Ratio }\end{array}$ & $\begin{array}{l}\text { Gene } \\
\text { Name }\end{array}$ & Product & $\begin{array}{c}\text { Common Pathways/Functional } \\
\text { Classifications }\end{array}$ \\
\hline PA0513 & 4.35 & 11.77 & nirG & Heme d1 biosynthesis protein & $\begin{array}{l}\text { Biosynthesis of heme d1/ } \\
\text { Denitrification/Energy metabolism }\end{array}$ \\
\hline PA0517 & 8.13 & 9.63 & nirC & Cytochrome c55X & $\begin{array}{l}\text { Biosynthesis of heme d1/ } \\
\text { Denitrification/Energy metabolism }\end{array}$ \\
\hline PA0518 & 8.48 & 17.32 & nirM & Cytochrome C-551 & $\begin{array}{l}\text { Biosynthesis of heme } \mathrm{d} 1 \\
\text { Denitrification/Energy metabolism }\end{array}$ \\
\hline PA0519 & 4.11 & 18.07 & nirs & Nitrite reductase & Denitrification/Energy metabolism \\
\hline PA0567 & 5.42 & 8.16 & yqaE & Hypothetical protein & Membrane proteins \\
\hline PA0887 & 5.63 & 17.12 & $\operatorname{acs} A$ & Acetyl-CoA synthetase & $\begin{array}{l}\text { Pyruvate metabolism/Central } \\
\text { intermediary metabolism }\end{array}$ \\
\hline PA0906 & 4.1 & 1.9 & alpR & & Transcriptional regulator \\
\hline PA1151 & 28.91 & $\infty$ & $i m m 2$ & Pyocin-S2 immunity protein & Adaptation and protection \\
\hline PA1243 & 4.72 & 4155.07 & & $\begin{array}{l}\text { Sensor/response regulator } \\
\text { hybrid protein }\end{array}$ & Two-component regulatory systems \\
\hline PA1705 & 4.04 & $\infty$ & pcrG & Type 3 secretion regulator & $\begin{array}{l}\text { Type } 3 \text { Secretion/Protein secretion/ } \\
\text { export apparatus }\end{array}$ \\
\hline PA1706 & 13.34 & $\infty$ & pcrV & Type 3 secretion protein & $\begin{array}{l}\text { Type } 3 \text { Secretion/Protein secretion/ } \\
\text { export apparatus }\end{array}$ \\
\hline PA1707 & 9.24 & $\infty$ & pcrH & Regulatory protein & $\begin{array}{l}\text { Type } 3 \text { Secretion/Protein secretion/ } \\
\text { export apparatus }\end{array}$ \\
\hline PA1708 & 16.04 & $\infty$ & popB & Translocator protein & $\begin{array}{l}\text { Type } 3 \text { Secretion/Protein secretion/ } \\
\text { export apparatus }\end{array}$ \\
\hline PA1710 & 17.64 & $\infty$ & exsC & Exoenzyme S synthesis protein & $\begin{array}{l}\text { Type } 3 \text { Secretion/Protein secretion/ } \\
\text { export apparatus }\end{array}$ \\
\hline PA1711 & 7.23 & $\infty$ & exsE & Hypothetical protein & $\begin{array}{l}\text { Type } 3 \text { Secretion/Protein secretion/ } \\
\text { export apparatus }\end{array}$ \\
\hline PA1718 & 86.42 & $\infty$ & pscE & Type 3 export protein & $\begin{array}{l}\text { Type } 3 \text { Secretion/Protein secretion/ } \\
\text { export apparatus }\end{array}$ \\
\hline PA1719 & 7.26 & $\infty$ & $p s c F$ & Type 3 export protein & $\begin{array}{l}\text { Type } 3 \text { Secretion/Protein secretion/ } \\
\text { export apparatus }\end{array}$ \\
\hline PA1930 & 16.66 & 2989.98 & & Chemotaxis transducer & $\begin{array}{l}\text { Chemotaxis/Adaptation and } \\
\text { protection }\end{array}$ \\
\hline PA2142 & 6.04 & 5.36 & $y h x C$ & Short-chain dehydrogenase & Metabolic Enzymes \\
\hline PA2144 & 4.10 & 7.75 & $g \lg P$ & Glycogen phosphorylase & $\begin{array}{l}\text { Metabolic Enzymes/Cell wall/LPS/ } \\
\text { capsule }\end{array}$ \\
\hline PA2146 & 7.11 & 13.39 & yciG & Hypothetical protein & Metabolic Enzymes \\
\hline PA2147 & 9.02 & 22.08 & katE & Catalase HPII & $\begin{array}{l}\text { Metabolic Enzymes/Adaptation and } \\
\text { protection }\end{array}$ \\
\hline PA2152 & 4.68 & 10.97 & & Trehalose synthase & Metabolic Enzymes \\
\hline PA2158 & 5.54 & 9.22 & & Alcohol dehydrogenase & Metabolic Enzymes \\
\hline PA2164 & 4.01 & 7.95 & & Glycosyl hydrolase & $\begin{array}{l}\text { Metabolic Enzymes/Biosynthesis of } \\
\text { secondary metabolites }\end{array}$ \\
\hline PA2165 & 4.90 & 8.75 & $g \lg A$ & Glycogen synthase & $\begin{array}{l}\text { Metabolic Enzymes/Energy } \\
\text { metabolism }\end{array}$ \\
\hline PA2573 & 4.23 & 9.28 & & Chemotaxis transducer & $\begin{array}{l}\text { Chemotaxis/Adaptation and } \\
\text { protection }\end{array}$ \\
\hline PA3038 & 4.53 & 7.11 & opdQ & Porin & Transport of small molecules \\
\hline PA3187 & 6.13 & 38.98 & gltK & ATP-binding protein & ABC transporters/Glucose transport \\
\hline PA3188 & 10.20 & 8.50 & gltG & Probable permease & $\mathrm{ABC}$ transporters/Glucose transport \\
\hline PA3189 & 4.16 & 16.62 & gltF & Probable permease & ABC transporters/Glucose transport \\
\hline PA3190 & 8.18 & 47.30 & gltB & $\begin{array}{l}\text { Probable substrate-binding } \\
\text { protein }\end{array}$ & $\mathrm{ABC}$ transporters/Glucose transport \\
\hline
\end{tabular}




\begin{tabular}{|c|c|c|c|c|c|}
\hline PA3235 & 12.90 & 12.45 & yjcH & Hypothetical protein & Membrane protein \\
\hline PA3719 & 9.43 & 14.64 & armR & MexR anti-repressor ArmR & $\begin{array}{l}\text { Antibiotic resistance and } \\
\text { susceptibility/Beta-Lactam } \\
\text { resistance }\end{array}$ \\
\hline PA3721 & 5.60 & 10.64 & nalC & Transcriptional regulator & $\begin{array}{l}\text { Antibiotic resistance and } \\
\text { susceptibility/Beta-Lactam } \\
\text { resistance }\end{array}$ \\
\hline PA3841 & 6.55 & $\infty$ & exos & Exoenzyme S & Type 3 Secretion/Secreted toxin \\
\hline PA3842 & 16.24 & $\infty$ & spcS & Chaperone & $\begin{array}{l}\text { Type } 3 \text { Secretion/Chaperone \& heat } \\
\text { shock protein }\end{array}$ \\
\hline PA4171 & 8.91 & 9.94 & & Protease & Putative enzymes \\
\hline PA4218 & 4.55 & 6.43 & Amp & Transporter & $\begin{array}{l}\text { Antibiotic resistance and } \\
\text { susceptibility/Membrane proteins/ } \\
\text { Transport of small molecules }\end{array}$ \\
\hline PA4220 & 7.94 & 8.21 & fptB & Hypothetical protein & Hypothetical, unclassified, unknown \\
\hline PA4228 & 6.40 & 16.34 & pchD & $\begin{array}{l}\text { 2,3-dihydroxybenzoate-AMP } \\
\text { ligase }\end{array}$ & $\begin{array}{l}\text { Pyochelin synthesis/Transport of } \\
\text { small molecules }\end{array}$ \\
\hline PA4229 & 11.12 & 15.58 & pchC & Pyochelin biosynthetic protein & $\begin{array}{l}\text { Pyochelin synthesis/Transport of } \\
\text { small molecules }\end{array}$ \\
\hline PA4230 & 4.95 & 11.12 & pchB & Iso-chorismate-pyruvate lyase & $\begin{array}{l}\text { Pyochelin synthesis/Transport of } \\
\text { small molecules }\end{array}$ \\
\hline PA4231 & 4.83 & 12.66 & pchA & $\begin{array}{l}\text { Salicylate biosynthesis iso- } \\
\text { chorismate synthase }\end{array}$ & $\begin{array}{l}\text { Pyochelin synthesis/Transport of } \\
\text { small molecules }\end{array}$ \\
\hline PA4276 & 4.6 & 1.8 & SecE & & $\begin{array}{l}\text { Preprotein translocase subunit } \\
\text { SecE }\end{array}$ \\
\hline PA4738 & 9.22 & 6.48 & yjbJ & Hypothetical protein & $\begin{array}{l}\text { Metabolic pathways/Hypothetical, } \\
\text { unclassified, unknown }\end{array}$ \\
\hline PA4773 & 4.30 & 7.42 & speD2 & Hypothetical protein & $\begin{array}{l}\text { Metabolic pathways/Hypothetical, } \\
\text { unclassified, unknown }\end{array}$ \\
\hline PA4915 & 15.31 & 125.79 & & Chemotaxis transducer & $\begin{array}{l}\text { Chemotaxis/Adaptation and } \\
\text { protection/Two-component system }\end{array}$ \\
\hline PA5240 & 9.0 & 1.4 & $\operatorname{tr} x A$ & & Thioredoxin \\
\hline
\end{tabular}

acute strain CMC-115 versus the chronic strain CMC097 by more than four-fold out of a total of 5,549 gene probesets on the array (The full microarray analysis with fold changes and p-values is contained Supplementary Table S1).

Fifty-six of the four-fold differentially expressed genes were annotated only as encoding "hypothetical" proteins with no putative function and may be fruitful subjects for future laboratory studies of virulence factors in acute and chronic infections. Here we will focus on the remaining 95 transcripts with identified names, synonyms, and functions in the fully annotated PAO1 reference genome (NC_002516) or the Pseudomonas Genome Database. Table 2 shows that the 46 annotated transcripts more highly expressed 4-fold or more in the acute isolate, CMC-115, clearly group into five different virulence specific gene clusters as follows: 1) Multidrug efflux pump genes (mexG, mexH, mexl and opmD); 2) Genes involved in flagella (flic, flaG, fliD and fliS); 3) Type 6 secretory system (T6SS) genes ( $h$ siB3, hsiC3, hcP3 and hsiF3), 4) Phenazine biosynthesis genes (phzD2, phzE2 and $p h z F 2$ ); and 5) Pyoverdine biosynthesis genes ( $p v d Q$, $p v d M, p v d N$ and $p v d O)$. Moreover, Table 3 shows that the 49 annotated transcripts highly expressed 4-fold or more in the chronic isolate, CMC-097, were grouped into six separate virulence and metabolic specific gene clusters as follows: 1 ) Glucose transporters (gltK, gltG, $g / t F$, and $g(t B) ; 2)$ Metabolic enzymes ( $y h x C, g / g P, y c i G$, katE, and $g(g A)$; 3) Heme biosynthesis/denitrification genes (nirG, nirC, nirM and nirS), 4) Pyochelin biosynthesis genes $(p c h D, p c h C, p c h B$ and $p c h A)$; and 5) Type 3 secretory system (T3SS) genes belonging to the translocation apparatus, including a needle-tip complex $(p c r V)$, translocon ( $p o p B)$, chaperones (pcrG and $p c r H)$, regulatory (exs) genes (e.g., exs $C$ and exsE), and needle biogenesis encoded by the psc genes (e.g.,pscE and $p s c F)$; and 6) The T3SS effector toxin gene (exoS) and its chaperone $(s p c S)$. These variable expression patterns, encompassing entire biological pathways, indicate that these clinical strains for acute and chronic infections represent two disparate isolates from the same bacterial species.

\section{RNA-Seq Analysis for the CMC-097 and CMC-115 Clinical Strains of $P$. aeruginosa}

RNA-Seq data was generated from three biological replicates for the two different clinical strains of $P$. aeruginosa, CMC-097 and CMC-115, at early-stationary growth phase in culture (five-hour time point). The 
Table 4: RNA-Seq read counts.

\begin{tabular}{|c|c|c|c|}
\hline Sample $^{*}$ & Paired End Reads & Mapped Reads & Unmapped Reads \\
\hline PA97a & $125,718,442$ & $123,805,708$ & $1,912,734$ \\
\hline PA9 & $125,240,896$ & $122,781,429$ & $2,459,467$ \\
\hline 7b & $146,862,240$ & $144,239,844$ & $2,622,396$ \\
\hline PA97c2 & $133,782,560$ & $131,682,656$ & $2,099,904$ \\
\hline PA115a & $151,215,796$ & $148,950,486$ & $2,265,310$ \\
\hline PA115b & $302,358,818$ & $297,555,782$ & $4,803,036$ \\
\hline
\end{tabular}

${ }^{*}$ Read Counts for each Sample was done by using Geneious 11.
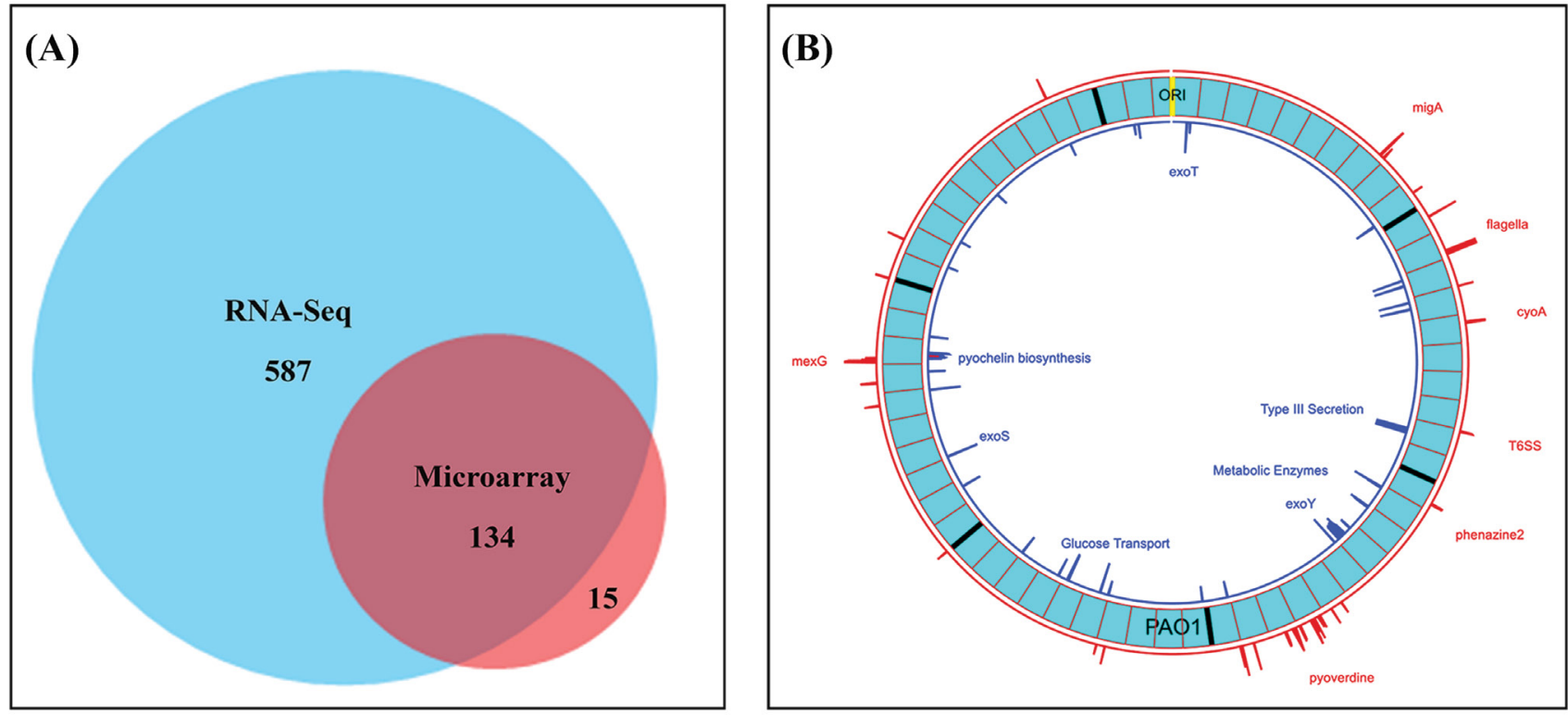

Figure 3: Venn diagram shows validation of gene expression measurements using DNA microarray and RNA-Seq and Circular Plot represents the loci of 4-Fold or greater differences of gene expression levels on the PAO1 genome. A) Number of genes at least 4-fold changed between CMC-97 and CMC-115 using PAO1 as a reference using RNA-seq and DNAmicroarrays. Note: For the 15 genes identified only by DNA microarrays there were often large numbers of SNPs between the two strains; B) Circos plot created with Circa (http://omgenomics.com/circa). The loci of 4-fold or greater expression for CMC-115 (red) and CMC-097 (blue) are plotted relative to the circular, 6.24 Mbp PAO1 Reference genome (light blue, with major tick marks indicating multiples of $1 \mathrm{Mbp}$ and minor tick marks indicating $100 \mathrm{Kbp}$ divisions relative to the ORI). The log2 of the expression Ratio is plotted for all genes with 4-Fold changes ranging from a height of 2 to the maximum height capped at 6 (64-fold difference).

fastq files containing the sequencing reads, along with quality scores for each nucleotide, were analyzed using the Geneious RNA-Seq data analysis pipeline. More than 125 million Illumina paired-end reads were generated for each of the six samples and greater than $98 \%$ of the reads were mapped by Geneious to the PAO1 reference genome (NC_002516) with at most $10 \%$ mismatch. Details of the sequencing results are provided in Table 4.

\section{Quantifying transcript abundance}

Geneious read alignments for each sample were used to determine the normalized gene expression levels in TPM using the "Calculate Expression Levels" command for the 5572 gene sequences annotated in the PAO1 reference genome. Then the expression foldchanges between the CMC-115 and CMC-097 samples were computed by taking the ratio of the averages of the TPM results for the three replicates. (The complete
RNA-Seq analysis with fold changes and $p$-values is contained in Supplementary Table S2).

Due to the greater sensitivity and specificity of the RNA-Seq transcriptome analysis, many more genes were found to be differentially expressed 4-fold or more between the two strains. The RNA-Seq analysis identified 587 genes with 4-fold or greater changes in expression between the acute, CMC-115, and chronic, CMC-097 strains (Supplementary Table S3).

Of the 151 gene probesets found to be greater than 4-fold changed on the DNA microarrays, only 149 are still annotated in the current PAO1 genome (NC_002516). (PA2456 was discontinued and PA4527 is pseudogene). The RNA-Seq results confirmed $90 \%$ (134/149) of these 4-fold changes as shown in the Venn Diagram (Figure $3 \mathrm{~A}$ ) including 87 of the 95 annotated genes in Table 2 and Table 3. 
The RNA-Seq analysis provided further support for the functional interpretation of the differences between the two strains by identifying additional members of differentially expressed operons with greater than 4-fold changes. Moreover, the full RNA-Seq analysis also identified additional functional groups of genes that were clearly differentially expressed more than 4-fold between the two strains. In addition to the gene clusters found to be upregulated in CMC- 115 relative to CMC097 in the microarray analysis, the conventional RNASeq also identified operons with 1) Oxidation-reduction genes $c y o A, c y o B, c y o C, c y o D, c y o E$; and 2) $m i g A$, cat, tox $R$; and 3) Additional phenazine biosynthesis genes phzM, phzA1-phzG1, and phzS.

However, the RNA-Seq results for the three replicate measurements of the de-nitrification, nirG, nirC, nirM and nirS, genes were inconsistent (with large p-values) suggesting that the 4-fold increase in the chronic CMC097 strain might be an experimental artifact. Moreover, more stringent alignments of the RNA-Seq reads to the two nearly identical phenazine biosynthesis operons, $p h z 1$ and phz2 [45] revealed that the phz2 appear to be more highly expressed than phz1.

The loci of the most differentially expressed operons across the genome found by RNA-Seq are shown in the Circos plot and created with Circa (http://omgenomics. com/circa) in Figure 3B.

\section{Absence of T3SS gene expressions in CMC-115}

In some cases, the RNA-Seq analysis would find zero reads aligning to genes in all three replicates of one strain or the other, which leads to infinite fold change. In particular, the RNA-Seq analysis found zero reads detected for the genes of all three T3SS effector proteins and an exoenzyme $S$ synthesis protein, the exoT (PA0044), exoY (PA2191), exoS and spcS (PA3841PA3842), in the CMC-115 strain. The expression of 35 other T3SS associated genes (PA1691-PA1725) was also completely absent in the RNA-Seq analysis of the CMC115 strain, as listed in Supplementary Table S3. The absence of some of the T3SS genes identified by RNASeq transcripts in CMC-115 were also validated at both the transcript level by PCR and at the protein level by Western blots. For example, Figure 4A shows that the type 3 secretory translocator PcrV protein $(32-\mathrm{kDa})$ product was immuno-stained with $\mathrm{CMC}-097$ during growth phases but is completely absent in CMC-115. Moreover, PCR confirmed the $885 \mathrm{bp}$, pcrV (PA1706) gene was missing in Pa CMC-115 in Figure 4B. All these results suggest that the T3SS related genes are deleted from multiple locations in the genome of the CMC-115 acute infection strain compared with both the PAO1 reference strain and the CMC-097 chronic infection strain.

\section{Reliable vs. unreliable gene expression using the PAO1 reference sequence}

The $P$. aeruginosa RNA-Seq analysis was performed based on the PAO1 genome. While performing this analysis, we found that for some genes the RNA-Seq would seriously underestimate the number of mapped
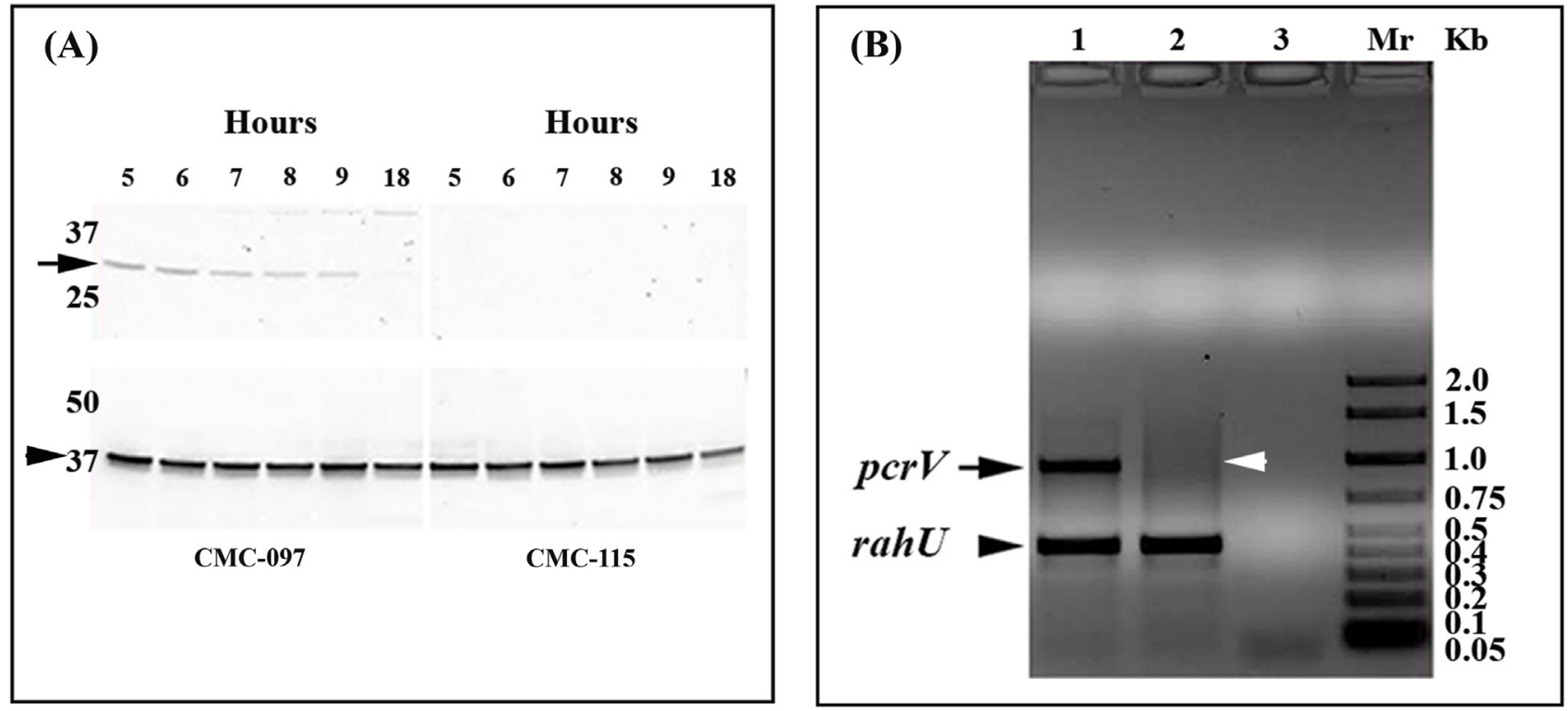

Figure 4: Western blot analysis for PcrV production and multiplex PCR amplification pcrV and rahU genes from CMC-115, CMC-097. A) Top panel, total protein extracts from the $\mathrm{Pa} C M C-115$ and CMC-097 were prepared at regular intervals between 5 and 9 and at $18 \mathrm{~h}$ after inoculation and the 32-kDa PcrV protein production (marked by arrow) was monitored. The blot results correspond to the sampling time points of the growth curves in Figure 1B. Bottom panel shows a 37-kDa, RpoA protein (indicated by arrowhead) used as control antibody. Shown is a representative of three independent experiments; B) A representative of an ethidium bromide stained $0.5 \%$ agarose gel, showing amplicon size for 885 bp pcrV gene in CMC097, in lane 1, and the absence of pcrV gene in CMC-115, in lane 2, represented by black arrowhead and white arrowhead, respectively. In both lanes (1 and 2), a $450 \mathrm{bp}$ size amplicon for rahU as used as control gene, Whereas, lane 3 is water control and laneMr is 2 Kbladder markers (Biorad). 
reads because individual gene sequences of $C M C-115$ or CMC-097 were highly divergent from PAO1. Therefore, very few reads would align using Geneious with less than $10 \%$ mismatch. A simple test for these "unreliable" genes was performed by repeating the Geneious "Map to Reference" using the "Medium Sensitivity" setting, which allows for up to $30 \%$ mismatch. An Unreliability Ratio (URatio) could then be computed using the ratio of the normalized TPM values for the 30\% matches divided by the TPM values for $10 \%$ matches. For most genes, these URatios are very close to 1 ; however, for the CMC-115 samples we found 91 unreliable genes (with URatios > 1.5) but only 44 for the CMC-097 samples (Supplementary Table S4 and Supplementary Table S5).

In particular, the unreliable genes for CMC-115 in Supplementary Table S4 include several members of the pyoverdine biosynthesis cluster. Both the RNASeq results and microarray results show that most pyoverdine biosynthesis genes are highly expressed, which is consistent with the green pyoverdine stains observed in CMC-115 cultures shown in Figure 1A. However, the RNA-Seq indicated some genes in the pyoverdine biosynthesis locus were down regulated in CMC-115. For example, Table 5 shows that the RNASeq and microarray ratios for (PA2390 - PA2395) are strongly increased in CMC-115, while the adjacent genes (PA2396 - PA2400) are not. This paradox can be resolved by noting that when the CMC-115 reads are mapped to the PAO1 gene sequences, allowing $30 \%$ mismatch instead of $10 \%$ mismatch, the $U$ Ratios of mapped reads for CMC-115 is much greater than 4 for the discordant genes, while it is closer to 1 for the concordant genes. Moreover, the CMC-097 U Ratios are close to 1 for all the genes. The results in Table 5 indicate that the discordance arises because the gene sequences for $p v d F$ through $p v d J$ in the CMC-115 strain are very different from the PAO1 reference while the sequences are very similar for the CMC-097 strain. It is important to note that this divergence in gene sequences will affect the interpretation of the expression measurements for both RNA-Seq and the DNA microarrays (with gene probsets designed based on the PAO1 sequences).

Moreover, the list of unreliable genes for CMC-097 in Supplementary Table S5 includes the flagellar genes, flgK - flis, as well at the pilA gene, that are all involved in bacterial motility. These results indicate that these gene loci are highly divergent from the PAO1 Reference genome, which may account for the observed decreased in the CMC-097 twitching motility shown in Figure 2A.

\section{The identification of multidrug-resistant genes in CMC-097}

Another advantage of the RNA-Seq analysis is that gene expression can be measured for genes that were not contained in either the PAO1 Reference genome or in the microarray design. For example, all the RNASeq reads can be aligned to the PAO1 Reference genome with high stringency using Geneious "Map to Reference" with the "Low Sensitivity/Fastest" setting that allows at most $10 \%$ mismatch. Then all the "Unused Reads" that failed to map to the Reference can be separately "De Novo" assembled using Geneious to generate contigs of gene sequences that are expressed

Table 5: Unreliability URatios for genes in the pyoverdine biosynthesis operon.

\begin{tabular}{|c|c|c|c|c|c|c|}
\hline Locus_tag & $\begin{array}{l}\text { Microarray } \\
\text { Ratio }\end{array}$ & RNA-Seq Ratio & URatioCMC-115 & URatioCMC-097 & Gene Name & Product \\
\hline PA2390 & 2.22 & 5.07 & 0.97 & 0.99 & $p v d T$ & $\begin{array}{l}\text { Pyoverdine biosynthesis } \\
\text { protein, PvdT }\end{array}$ \\
\hline PA2391 & 2.30 & 7.28 & 0.98 & 1.02 & opmQ & $\begin{array}{l}\text { Hypothetical protein, } \\
\text { OpmH }\end{array}$ \\
\hline PA2392 & 1.37 & 28.76 & 1.55 & 1.92 & $p v d P$ & $\begin{array}{l}\text { Pyoverdine biosynthesis } \\
\text { protein, PvdP }\end{array}$ \\
\hline PA2393 & 13.99 & 17.21 & 1.04 & 1.15 & & Dipeptidase \\
\hline PA2394 & 13.71 & 17.97 & 0.97 & 0.99 & $p v d N$ & $\begin{array}{l}\text { Pyoverdine biosynthesis } \\
\text { protein, PvdN }\end{array}$ \\
\hline PA2395 & 4.12 & 34.60 & 1.02 & 0.99 & $p v d O$ & $\begin{array}{l}\text { Pyoverdine biosynthesis } \\
\text { protein, PvdO }\end{array}$ \\
\hline PA2396 & 0.71 & 1.63 & 11.00 & 0.99 & $p v d F$ & $\begin{array}{l}\text { Pyoverdine synthetase } \\
\text { F, PvdF }\end{array}$ \\
\hline PA2397 & 1.10 & 0.03 & 103.14 & 0.99 & $p v d E$ & $\begin{array}{l}\text { Pyoverdine biosynthesis } \\
\text { protein, PvdE }\end{array}$ \\
\hline PA2398 & 0.58 & 0.00 & $\infty$ & 0.99 & $f p v A$ & $\begin{array}{l}\text { Ferripyoverdine } \\
\text { receptor, fpvA }\end{array}$ \\
\hline PA2399 & 0.60 & 0.01 & 39.39 & 0.99 & $p v d D$ & $\begin{array}{l}\text { Pyoverdine synthetase } \\
\text { D, PvdB }\end{array}$ \\
\hline PA2400 & 0.90 & 0.10 & 5.79 & 1.00 & $p v d J$ & $\begin{array}{l}\text { Pyoverdine biosynthesis } \\
\text { protein PvdJ }\end{array}$ \\
\hline
\end{tabular}


but are either not present in the Reference or are highly divergent. These contigs can then be annotated using RAST [46] to identify novel gene sequences. In this manner, we readily identified an operon containing genes for aminoglycoside acetyltransferase gene (aacA27), $\beta$-lactamase ${ }_{\mathrm{OXA}-2} \quad\left(b_{1} a_{\mathrm{OXA}-2}\right), \quad$ a truncated quaternary ammonium compound efflux (qacE $\Delta 1$ ) and sulfonamides (su/1), and the acetyltransferase family (GNAT) in CMC-097 strain. A similar analysis of the gene content in the contigs assembled from the "Unused Reads" for Pa CMC-115 showed no evidence of this bla operon. These results are consistent with the antimicrobial susceptibility testing for these two strains shown in Table 1.

\section{Discussion}

Pseudomonas aeruginosa $(\mathrm{Pa})$ is an opportunistic pathogen that is a leading cause of nosocomial pneumonia [47] with high rates of morbidity and mortality $[4,48]$. Clinical presentations of $P a$ infections can be either acute or chronic, with distinct manifestations, disease progression, and antibiotic resistance profiles [49]. In this study, we have performed a comparative transcriptomic analysis of two different $P a$ strains isolated from ICU patients on ventilators, one with acute and one with chronic pneumonia, in order to gain a better understanding of virulence factors involved in pathogenesis and identify multidrug-resistant genes or novel pathway targets [50-52] for treatments. The two clinical strains of $P a C M C-115$ from an acute infection and CMC-097 from a chronic infection, were selected based on clinical evaluation and phenotypic differences identified in culture. Both DNA microarray and RNA-Seq technologies were used to identify over 100 genes that were differentially expressed by factors of 4-fold or more in key virulence related operons. The key functional differences in virulence operons are summarized in Table 6A and Table 6B. These results confirmed many observations of previous studies, but a detailed comparison of the DNA microarray and RNASeq results revealed several surprises.

Table 6A: Virulence genes Up-regulated in Pa CMC-115.

\begin{tabular}{|c|c|c|c|}
\hline Functions & Gene Name & Microarray Fold Ratio & RNA-Seq Fold Ratio \\
\hline \multirow{3}{*}{ Phenazine } & phzD2 & 5.07 & 4.95 \\
\hline & phzF2 & 4.9 & 5.09 \\
\hline & phzE2 & 4.8 & 5.17 \\
\hline \multirow{4}{*}{ Pyoverdine } & $p v d M$ & 13.99 & 17.21 \\
\hline & $p v d N$ & 13.71 & 17.97 \\
\hline & $p v d Q$ & 5.62 & 20.24 \\
\hline & $p v d O$ & 4.12 & 34.6 \\
\hline \multirow{4}{*}{ Ferripyoverdine receptor } & $f p v H$ & 9.09 & 5.09 \\
\hline & $f p v J$ & 6.08 & 7.27 \\
\hline & fpvK & 4.56 & 4.46 \\
\hline & $f p v C$ & 4.04 & 5.56 \\
\hline
\end{tabular}

Table 6B: Virulence genes Up-regulated in Pa CMC-097.

\begin{tabular}{|c|c|c|c|}
\hline Functions & Gene Name & $\begin{array}{l}\text { Microarray* } \\
\text { Fold Ratio }\end{array}$ & $\begin{array}{l}\text { RNA-Seq } \\
\text { Fold Ratio }\end{array}$ \\
\hline \multirow{10}{*}{ Type 3 secretion } & pscE & 86.42 & $\infty$ \\
\hline & exsC & 17.64 & $\infty$ \\
\hline & spcS & 16.24 & $\infty$ \\
\hline & popB & 16.04 & $\infty$ \\
\hline & $p c r V$ & 13.34 & $\infty$ \\
\hline & pcrH & 9.24 & $\infty$ \\
\hline & $p s c F$ & 7.26 & $\infty$ \\
\hline & exsE & 7.23 & $\infty$ \\
\hline & exos & 6.55 & $\infty$ \\
\hline & pcrG & 4.04 & $\infty$ \\
\hline \multirow{4}{*}{ Pyochelin } & pchC & 11.12 & 15.58 \\
\hline & pchD & 6.4 & 16.34 \\
\hline & pchB & 4.95 & 11.12 \\
\hline & pchA & 4.83 & 12.66 \\
\hline
\end{tabular}


Previous studies have shown that the acute infection process is initiated by free cells that express a wide variety of acute virulence factors, including QSregulated virulence factors such as proteases, elastases, phenazines, pyoverdine, toxins [53]; and type 3 secretion system (T3SS) genes [54]. We similarly found that the acute strain, CMC-115 has enhanced expression of pyoverdine genes, compared with the chronic strain CMC-097, resulting in distinct green pigmented colonies in culture. Phenazine genes were also more highly expressed in the acute strain. However, the RNA-Seq data indicated that the expression of the T3SS and its effector genes were completely absent in the acute strain, CMC-115. In contrast, chronic infections involve a slow colonization process with different virulence factors. One important difference that we see in the chronic strain, CMC-097, is enhanced expression of pyochelin genes [55]. We also find a full complement of the T3SS genes as well as key multidrug resistance genes in the chronic strain, CMC-097.

The combination of the DNA microarray and RNA-Seq analysis used in our study was able to transcend these general distinctions between the acute and chronic $\mathrm{Pa}$ strains to reveal greater details related to the different strategies for iron uptake in the two strains [56] and the role of two distinct phenazine operons in the $\mathrm{Pa}$ genomes [57]. For example, previous work has recognized that $\mathrm{Pa}$ can use different mechanisms to acquire iron 1) By pyoverdine-mediated uptake through tonB-dependent receptors, like fpvA, 2) By pyochelin-mediated uptake through the FptA ferripyochelin receptor [56], and 3) By phenazine-mediated iron uptake through the outer membrane proteins (porin), and the FeoB receptor [58]. In particular, previous work [56] has shown that the pyoverdine siderophores, which have a high affinity for iron binding, are key players in the virulence of acute infections [59], both as iron chelators and as signal molecules for the production of other virulence factors $[60,61]$. Earlier, we have also found that infection by the acute strain, CMC-115, is highly lethal in a mouse model, where the aggressive iron scavenging from the host may be responsible for the increased virulence [62]. In contrast, the pyochelin siderophores, which have lower affinity for iron binding, [56] appear to play a more important role in the prolonged, chronic infections $[63,64]$. In our previous mouse model study [62], we found that mouse mortality was greatly reduced with the chronic, CMC-097, infection.

Our comparative transcriptomic analyses (summarized in Table 6A and Table 6B) clearly showed that the operon containing pyoverdine synthesis and receptor genes was more highly expressed in acute strain, CMC-115, and that the operon containing pyochelin synthesis genes had much greater expression in chronic strain, CMC-097, suggesting that the two strains utilize these two different strategies for iron acquisition. However, our RNA-Seq analysis also revealed that not only are the pyoverdine-related genes significantly up-regulated in the acute strain but several of these genes are highly divergent from corresponding genes in the PAO1 reference genome or the chronic strain CMC-097. These genes were identified using the URatio strategy for detecting unreliable genes. For example, Table 4 shows that the key ferripyoverdine gene, $f p v A$, was very different from the PAO1 reference sequence, and even allowing $30 \%$ mismatch there were no reads mapped. A careful assembly of the RNA-Seq reads for $\mathrm{CMC}-115$ permitted a reconstruction of this gene to reveal that it was a fpvA Type IIb [65]. This result was also confirmed by our recent complete assembly of the CMC-115 genome [66]. It is also interesting to note that a previous study has found that pyoverdine locus is one of the most diversified regions in several cystic fibrosis and environmental strains $[63,64]$.

Another important difference between the two strains, shown in Table 6A, was the enhanced expression in the acute strain of phenazine biosynthesis genes ( $p h z)$, which produce the secondary metabolites phenazine-1-carboxylic acid (PCA) and pyocyanin [57] and also play a role in iron uptake in $P a$ [56]. Moreover, the $p h z$ metabolites have been found to be involved in CF patients' lungs and responsible for progressive lung tissue destruction, leading to respiratory failure [67].

$\mathrm{Pa}$ genomes typically contain two nearly identical copies of the $p h z$ biosynthesis gene operons, phz1 and phz2, which are so similar that the expression cannot be easily distinguished on DNA microarrays or conventional RNA-Seq analysis [45]. By mapping the RNA-Seq reads for both strains with high stringency to the more variable segments of the phz genes, we confirmed that the phz2 operon was expressed as much as 4-fold or more compared with the phz1 operon in both cases. This is consistent with a recent RNA-Seq study of the quorum sensing regulation of phenazine gene expression that also found the average expression level of $p h z 2$ genes was much higher than that of phz1 [68].

Overall, the DNA microarray results comparing the gene expression levels of the two strains provided an excellent overview of key virulence factors that are differentially expressed between the acute and chronic strains of $P a$ in this study. However, the comparison of the microarray and RNA-Seq results revealed a few new results and challenges. For example, when comparing the gene expression levels between two strains of the same microbial species, we found that large levels (4fold or greater) in differential expression measured by DNA microarrays or conventional RNA-Seq (both using a common Reference genome, eg. PAO1) could arise either 1) Because similar genes in the two strains were truly expressed at different levels or 2) Because the gene sequence in one strain was very different from the Reference or 3) The gene was completely absent in one strain or the other. 
In particular, while we found that the DNA microarrays suggested that the genes for the T3SS structural proteins, translocators, and effectors had very low expression in the acute, CMC-115 strain compared to the chronic, CMC-097 strain, the RNA-Seq results gave zero reads mapping to most of these genes, indicating that the TS33 apparatus was completely absent from acute strain. This is denoted in Table 3 and Table $6 \mathrm{~B}$ as infinite expression. This conclusion was further validated by the absence of a translocation apparatus PcrV protein in CMC-115 by Western blotting (Figure $3 \mathrm{~A})$, and we recently confirmed the absence of T3SS genes in CMC-115 by whole genome sequencing [66].

Although it has been earlier believed that type 3 secretion system (T3SS) expression was necessary for increased $P$. aeruginosa virulence in murine models and human infections by adhesion and invasion into the host cell [15,69-72], T3SS-negative bacteria have been more recently identified in both acute and chronic infected patients as clinical and taxonomic outliers such as Strain JT87 and PA7 [73-76]. Strain JT87 was highly cytolytic in vitro, arguing that it may encode a novel virulence factor [74]. Hence, T3SS-independent, virulence strains such as CMC-115, which may utilize a different pathogenic repertoire in clinical disease, are deserving of further study.

In addition to the discovery of missing genes, the mapping of RNA-Seq reads to the Reference gene sequences at different levels of stringency readily revealed that some, often confusing, differential expression (like fpvA in Table 4) was due to divergence of gene sequences in one strain or the other, causing "unreliable" gene counts. Both the identification of missing genes and highly divergent genes suggest the value of always assembling a complete genome sequence for each strain in a comparative transcriptome analysis. In fact, we have recently completed for the acute strain, CMC-115, and the chronic strain, CMC097 (GenBank Accession Numbers CP046602 and CP065848), respectively.

Finally, the RNA-Seq data proved useful for identifying novel genes of clinical significance because the RNASeq reads failed to map to the PAO1 reference genome and de novo assembled to reconstruct a MDR locus. For the first time in Southwest Virginia, we identified a MDR locus containing aac27, bla $a_{\mathrm{OXA}-2}$ qacE 1 , sul1, and GNAT, which has been subsequently Confirmed by INTEGRALL [77] to be part of a novel In2020 in the main chromosome of CMC-097 (CP065848).

In summary, the addition of the RNA-Seq analysis not only validated the main findings of the DNA microarray results for gene expression differences between the acute and chronic $P$. aeruginosa strains, it also provided valuable insight into the distinct reasons for differential gene expression measurements in a comparative transcriptomic study, as well as the identification of novel virulence and multidrug resistance genes. Thus, a better understanding of the virulence mechanisms of $\mathrm{Pa}$ is an important step in the development of prospective therapeutic targets and intervention methods for the treatment of hospital-acquired pneumonia.

\section{Acknowledgements}

We acknowledge the faculty members of the Division of Infectious Disease, Carilion Clinic, and Carilion's clinical microbiology laboratory for their assistance in collecting patient samples under Carilion institutional review board (IRB) approved study. Experiments were carried out at the CBSRL, Carilion Roanoke Community Hospital. This study was supported by the Carilion Research Acceleration Program 5 grant to D.C.G. and J.R., Thomas F. and Kate Miller Jeffress Memorial Trust funding for J.R., and L.C. was supported by Virginia Polytechnic Institute and State University (VT), and J. M. $G$, an undergraduate student and his research supply was granted from the Capstone research program by the Jefferson College of Health Sciences; now it is renamed as Radford University Carilion (RUC). We are thankful to Susan Toliver, laboratory manager, Department of Science laboratory and Sarah Cox, at the RUC, for their valuable support in reagents procuring on manuscript reading and their suggestions.

\section{References}

1. Waters B, Muscedere J (2015) A 2015 Update on VentilatorAssociated Pneumonia: New Insights on Its Prevention, Diagnosis, and Treatment. Curr Infect Dis Rep 17: 496.

2. Williams BJ, Dehnbostel J, Blackwell TS (2010) Pseudomonas aeruginosa: host defence in lung diseases. Respirology 15: 1037-1056.

3. Rello J, Ausino V, Ricart M, Castella J, Prats G (1993) Impact of Previous Antimicrobial Therapy on the Etiology and Outcome of Ventilator-associated Pneumonia. Chest 104: $1230-1235$.

4. Klompas M (2019) Ventilator-Associated Events: What They Are and What They Are Not. Respir Care 64: 953.

5. Tacconelli E, Carrara E, Savoldi A, Harbarth S, Mendelson $M$, et al. (2018) Discovery, research, and development of new antibiotics: the WHO priority list of antibiotic-resistant bacteria and tuberculosis. Lancet Infect Dis 18: 318-327.

6. Lee J, Zhang L (2015) The hierarchy quorum sensing network in Pseudomonas aeruginosa. Protein Cell 6: 26-41.

7. Rao J, DiGiandomenico A, Unger J, Bao Y, PolanowskaGrabowska RK (2008) A novel oxidized low-density lipoprotein-binding protein from Pseudomonas aeruginosa. Microbiology 154: 654-665.

8. Rao J, Damron FH, Basler M, DiGiandomenico A, Sherman NE, et al. (2011) Comparisons of Two Proteomic Analyses of Non-Mucoid and Mucoid Pseudomonas aeruginosa Clinical Isolates from a Cystic Fibrosis Patient. Front Microbiol 2: 162.

9. Imperi F, Ciccosanti F, Perdomo AB, Tiburzi F, Mancone $C$, et al. (2009) Analysis of the periplasmic proteome of Pseudomonas aeruginosa, a metabolically versatile opportunistic pathogen. Proteomics 9: 1901-1915. 
10. Platt MD, Schurr MJ, Sauer K, Vazquez G, KukavicaIbrulj I, et al. (2008) Proteomic, microarray, and signaturetagged mutagenesis analyses of anaerobic Pseudomonas aeruginosa at $\mathrm{pH} 6.5$, likely representing chronic, late-stage cystic fibrosis airway conditions. J Bacteriol 190: 27392758 .

11. Turner KH, Everett J, Trivedi U, Rumbaugh KP, Whiteley M (2014) Requirements for Pseudomonas aeruginosa acute burn and chronic surgical wound infection. PLoS Genet 10: e1004518.

12. Furukawa S, Kuchma SL, Toole GA (2006) Keeping Their Options Open: Acute versus Persistent Infections. J Bacteriol 188: 1211.

13. Walters MS, Grass JE, Bulens SN, Hancock EB, Phipps EC, et al. (2019) Carbapenem-Resistant Pseudomonas aeruginosa at US Emerging Infections Program Sites, 2015. Emerg Infect Dis 25: 1281-1288.

14. Mulet X, Cabot G, Ocampo-Sosa AA, Domínguez MA, Zamorano L, et al. (2013) Biological markers of Pseudomonas aeruginosa epidemic high-risk clones. Antimicrob Agents Chemother 57: 5527-5535.

15. Juan C, Pena C, Oliver A (2017) Host and Pathogen Biomarkers for Severe Pseudomonas aeruginosa Infections. J Infect Dis 215: S44-S51.

16. Codjoe SF, Donkor SE (2018) Carbapenem Resistance: A Review. Med Sci (Basel) 6: 1-28.

17. Pitt TL, Barth AL (1997) Pseudomonas aeruginosa and other medically important pseudomonads. In: Emmerson AM, Hawkey PM, Gillespie SH, Principles and practice of clinical bacteriology. London: John Wiley \& Sons, 493-517.

18. Vasil ML, Ochsner UA (1999) The response of Pseudomonas aeruginosa to iron: genetics, biochemistry and virulence. Mol Microbiol 34: 399-413.

19. Marvig RL, Damkiaer S, Khademi SMH, Markussen TM, Molin S, et al. (2014) Within-Host Evolution of Pseudomonas aeruginosa Reveals Adaptation toward Iron Acquisition from Hemoglobin. mBio 5.

20. Damron FH, Oglesby-Sherrouse AG, Wilks A, Barbier M (2016) Dual-seq transcriptomics reveals the battle for iron during Pseudomonas aeruginosa acute murine pneumonia. Scientific Reports 6: 39172

21. Mavrodi DV, Bonsall RF, Delaney SM, Soule MJ, Phillips G, et al. (2001) Functional analysis of genes for biosynthesis of pyocyanin and phenazine-1-carboxamide from Pseudomonas aeruginosa PAO1. J Bacteriol 183: 64546465.

22. Finnan S, Morrissey JP, O'Gara F, Boyd EF (2004) Genome diversity of Pseudomonas aeruginosa isolates from cystic fibrosis patients and the hospital environment. $J$ Clin Microbiol 42: 5783-5792.

23. Marty N, Pasquier C, Dournes JL, Chemin K, Chavagnat F, et al. (1998) Effects of characterised Pseudomonas aeruginosa exopolysaccharides on adherence to human tracheal cells. Journal of Medical Microbiology 47: 129-134.

24. Pier GB, Coleman F, Grout M, Franklin M, Ohman DE (2001) Role of alginate $O$ acetylation in resistance of mucoid Pseudomonas aeruginosa to opsonic phagocytosis. Infect Immun 69: 1895-1901.

25. Borriello G, Werner E, Roe F, Kim AM, Ehrlich GD, et al (2004) Oxygen Limitation Contributes to Antibiotic Tolerance of Pseudomonas aeruginosa in Biofilms. Antimicrob Agents Chemother 48: 2659-2664.
26. Simpson JA, Smith SE, Dean RT (1989) Scavenging by alginate of free radicals released by macrophages. Free Radical Biology \& Medicine 6: 347-353.

27. Lapouge K, Schubert M, Allain FH, Haas D (2008) Gac/ Rsm signal transduction pathway of gamma-proteobacteria: from RNA recognition to regulation of social behaviour. Mol Microbiol 67: 241-253.

28. Hirsch EB, Tam VH (2010) Impact of multidrug-resistant Pseudomonas aeruginosa infection on patient outcomes. Expert Rev Pharmacoecon Outcomes Res 10: 441-451.

29. Buehrle DJ, Shields RK, Clarke LG, Potoski BA, Clancy CJ, et al. (2016) Carbapenem-Resistant Pseudomonas aeruginosa Bacteremia: Risk Factors for Mortality and Microbiologic Treatment Failure. Antimicrob Agents Chemother 61: e01243-16.

30. Aloush V, Navon-Venezia S, Seigman-Igra Y, Cabili S, Carmeli Y (2006) Multidrug-resistant Pseudomonas aeruginosa: risk factors and clinical impact. Antimicrob Agents Chemother 50: 43-48.

31. von Klitzing E, Ekmekciu I, Kühl AA, Bereswill S, Heimesaat MM (2018) Multidrug-resistant Pseudomonas aeruginosa aggravates inflammatory responses in murine chronic colitis. Scientific Reports 8: 6685.

32. Rossi Goncalves I, Dantas RCC, Ferreira ML, Batistão DWdF, Gontijo-Filho PP, et al. (2017) Carbapenemresistant Pseudomonas aeruginosa: association with virulence genes and biofilm formation. Braz $\mathrm{J}$ Microbiol 48: 211-217.

33. Turner KH, Wessel AK, Palmer GC, Murray JL, Whiteley M (2015) Essential genome of Pseudomonas aeruginosa in cystic fibrosis sputum. Proc Natl Acad Sci USA 112: 41104115.

34. Son MS, Matthews WJ Jr, Kang Y, Nguyen DT, Hoang TT (2007) In Vivo Evidence of Pseudomonas aeruginosa Nutrient Acquisition and Pathogenesis in the Lungs of Cystic Fibrosis Patients. Infect Immun 75: 5313-5324.

35. Campodonico VL, Gadjeva M, Paradis-Bleau C, Uluer A, Pier GB (2008) Airway epithelial control of Pseudomonas aeruginosa infection in cystic fibrosis. Trends Mol Med 14: 120-133.

36. Goldberg JB, Pier GB (2000) The role of the CFTR in susceptibility to Pseudomonas aeruginosa infections in cystic fibrosis. Trends Microbiol 8: 514-520.

37. Klockgether J, Cramer N, Wiehlmann L, Davenport CF, Tummler B (2011) Pseudomonas aeruginosa Genomic Structure and Diversity. Front Microbiol 2: 150.

38. Stover CK, Pham XQ, Erwin AL, Mizoguchi SD, Warrener P, et al. (2000) Complete genome sequence of Pseudomonas aeruginosa PA01, an opportunistic pathogen. Nature 406: 959-964.

39. Lindhout T, Lau PC, Brewer D, Lam JS (2009) Truncation in the core oligosaccharide of lipopolysaccharide affects flagella-mediated motility in Pseudomonas aeruginosa PAO1 via modulation of cell surface attachment. Microbiology 155: 3449-3460.

40. Sass G, Nazik H, Penner J, Shah H, Ansari SR, et al. (2018) Studies of Pseudomonas aeruginosa Mutants Indicate Pyoverdine as the Central Factor in Inhibition of Aspergillus fumigatus Biofilm. J Bacteriol 200: 00345-17.

41. Laemmli UK (1970) Cleavage of structural proteins during the assembly of the head of bacteriophage T4. Nature 227: $680-685$ 
42. Rao J, Susanti D, Childress JC, Mitkos MC, Brima JK, et al. (2018) Tn2008-driven carbapenem resistance in Acinetobacter baumannii isolates from a period of increased incidence of infections in a Southwest Virginia hospital (USA). Journal of Global Antimicrobial Resistance 12: $79-87$.

43. Markelz AE, Mende K, Murray CK, Yu X, Zera WC, et al. (2011) Carbapenem susceptibility testing errors using three automated systems, disk diffusion, Etest, and broth microdilution and carbapenem resistance genes in isolates of Acinetobacter baumannii-calcoaceticus complex. Antimicrob Agents Chemother 55: 4707-4711.

44. CLSI (2017) Performance Standards for Antimicrobial Susceptibility Testing. Wayne, PA: Clinical and Laboratory Standards Institute.

45. Higgins S, Heeb S, Rampioni G, Fletcher MP, Williams $P$, et al. (2018) Differential Regulation of the Phenazine Biosynthetic Operons by Quorum Sensing in Pseudomonas aeruginosa PAO1-N. Frontiers in Cellular and Infection Microbiology 8: 252.

46. Aziz RK, Bartels D, Best AA, DeJongh M, Disz T, et al. (2008) The RAST Server: rapid annotations using subsystems technology. BMC Genomics 9: 75.

47. Emori TG, Gaynes RP (1993) An overview of nosocomial infections, including the role of the microbiology laboratory. Clin Microbiol Rev 6: 428-442.

48. Kalil AC, Metersky ML, Klompas M, Muscedere J, Sweeney DA, et al. (2016) Management of Adults With Hospitalacquired and Ventilator-associated Pneumonia: 2016 Clinical Practice Guidelines by the Infectious Diseases Society of America and the American Thoracic Society. Clin Infect Dis 63: e61-e111.

49. Lister PD, Wolter DJ, Hanson ND (2009) Antibacterialresistant Pseudomonas aeruginosa: Clinical impact and complex regulation of chromosomally encoded resistance mechanisms. Clin Microbiol Rev 22: 582-610.

50. Karaiskos I, Giamarellou H (2014) Multidrug-resistant and extensively drug-resistant Gram-negative pathogens: current and emerging therapeutic approaches. Expert Opin Pharmacother 15: 1351-1370.

51. Navon-Venezia S, Kondratyeva K, Carattoli A (2017) Klebsiella pneumoniae: a major worldwide source and shuttle for antibiotic resistance. FEMS Microbiol Rev 41: 252-275.

52. Gilad J, Carmeli Y (2008) Treatment options for multidrug resistant Acinetobacter species. Drugs 68: 165-189.

53. Williams P, Camara M (2009) Quorum sensing and environmental adaptation in Pseudomonas aeruginosa: A tale of regulatory networks and multifunctional signal molecules. Curr Opin Microbiol 12: 182-191.

54. Hauser AR (2009) The type III secretion system of Pseudomonas aeruginosa: infection by injection. Nat Rev Microbiol 7: 654-665.

55. Harrison F, McNally A, da Silva AC, Heeb S, Diggle SP (2017) Optimised chronic infection models demonstrate that siderophore 'cheating' in Pseudomonas aeruginosa is context specific. ISME J 11: 2492-2509.

56. Cornelis P, Dingemans J (2013) Pseudomonas aeruginosa adapts its iron uptake strategies in function of the type of infections. Front Cell Infect Microbiol 3: 75.

57. Cui Q, Lv H, Qi Z, Jiang B, Xiao B, et al. (2016) CrossRegulation between the phz1 and phz2 Operons Maintain a
Balanced Level of Phenazine Biosynthesis in Pseudomonas aeruginosa PAO1. PLoS One 11: e0144447.

58. Cartron ML, Maddocks S, Gillingham P, Craven CJ, Andrews SC (2006) Feo--transport of ferrous iron into bacteria. Biometals 19: 143-157.

59. Kang D, Revtovich AV, Chen Q, Shah KN, Cannon CL, et al. (2019) Pyoverdine-Dependent Virulence of Pseudomonas aeruginosa Isolates From Cystic Fibrosis Patients. Frontiers in Microbiology 10: 2048.

60. Meyer JM, Neely A, Stintzi A, Georges C, Holder IA (1996) Pyoverdin is essential for virulence of Pseudomonas aeruginosa. Infect Immun 64: 518-523.

61. Lamont IL, Beare PA, Ochsner U, Vasil AI, Vasil ML (2002) Siderophore-mediated signaling regulates virulence factor production in Pseudomonasaeruginosa. Proc Natl Acad Sci USA 99: 7072-7077.

62. Lily Colpitts, Kanevsky-Mullarky I, Garner DC, Leroith T, Kerkering TM, et al. (2013) Defining the Role of RahU Protein in Pathogenesis of Pseudomonas aeruginosa in a Murine Lung Infection Model. IDWeek 2013 Meeting of the Infectious Diseases Society of America.

63. Smith EE, Sims EH, Spencer DH, Kaul R, Olson MV (2005) Evidence for diversifying selection at the pyoverdine locus of Pseudomonas aeruginosa. J Bacteriol 187: 2138-2147.

64. Lyczak JB, Cannon CL, Pier GB (2002) Lung infections associated with cystic fibrosis. Clin Microbiol Rev 15: $194-$ 222.

65. Bodilis J, Ghysels B, Osayande J, Matthijs S, Pirnay JP, et al. (2009) Distribution and evolution of ferripyoverdine receptors in Pseudomonas aeruginosa. Environ Microbiol 11: 2123-2135.

66. Adenikinju A, Jensen RV, Kerkering TM, Garner DC, Rao J (2020) Complete Genome Sequence of Pseudompnas aeruginosa CMC-115, a Clinical Strain from an Acute Ventilator-Associated Pneumonia Patient. Microbiol Resour Announc 9: e00595-e00620.

67. Rada B, Leto TL (2013) Pyocyanin effects on respiratory epithelium: relevance in Pseudomonas aeruginosa airway infections. Trends Microbiol 21: 73-81.

68. Sun S, Zhou L, Jin K, Jiang H, He YW (2016) Quorum sensing systems differentially regulate the production of phenazine-1-carboxylic acid in the rhizobacterium Pseudomonas aeruginosa PA1201. Scientific Reports 6: 30352.

69. Ader F, Le BR, Faure K, Gosset P, Epaulard O, et al. (2005) Alveolar response to Pseudomonas aeruginosa: role of the type III secretion system. Infect Immun 73: 4263-4271.

70. Hueck CJ (1998) Type III protein secretion systems in bacterial pathogens of animals and plants. Microbiol Mol Biol Rev 62: 379-433.

71. Puhar A, Sansonetti PJ (2014) Type III secretion system. Curr Biol 24: R784-R791.

72. Williams McMackin EA, Djapgne L, Corley JM, Yahr TL (2019) Fitting Pieces into the Puzzle of Pseudomonas aeruginosa Type III Secretion System Gene Expression. J Bacteriol 201: e00209-e00219.

73. Rundell EA, McKeithen-Mead SA, Kazmierczak BI (2016) Rampant Cheating by Pathogens? PLoS Pathog 12: e1005792.

74. Czechowska K, McKeithen-Mead S, Al Moussawi K, Kazmierczak BI (2014) Cheating by type 3 secretion 
system-negative Pseudomonas aeruginosa during pulmonary infection. Proc Natl Acad Sci USA 111: 7801.

75. Elsen S, Huber P, Bouillot S, Coute, Y, Fournier P, et al. (2014) A type III secretion negative clinical strain of Pseudomonas aeruginosa employs a two-partner secreted exolysin to induce hemorrhagic pneumonia. Cell Host Microbe 15: 164-176.
76. Toska J, Sun Y, Carbonell DA, Foster AN, Jacobs MR, et al. (2014) Diversity of Virulence Phenotypes among Type III Secretion Negative Pseudomonas aeruginosa Clinical Isolates. PLoS One 9: e86829.

77. Moura A, Soares M, Pereira C, Leitao N, Henriques I, et al. (2009) INTEGRALL: a database and search engine for integrons, integrases and gene cassettes. Bioinformatics 25: 1096-1098. 